\title{
Dietary encapsulated essential oils and organic acids mixture improves gut health in broiler chickens challenged with necrotic enteritis
}

Van Hieu Pham 1,2, Liugang Kan', Jinyu Huang ${ }^{3}$, Yanqiang Geng' ', Wenrui Zhen', Yuming Guo', Waseem Abbas ${ }^{1}$ and Zhong Wang ${ }^{1 *}$ (D)

\begin{abstract}
Background: The poultry industry is in need of effective antibiotic alternatives to control outbreaks of necrotic enteritis (NE) due to Clostridium perfringens. In the present study, we investigated the effects of dietary supplementation with a blend of encapsulated essential oils and organic acids (BLJ) on growth performance and gut health using a coinfection model of NE in broiler chickens.

Methods: Two hundred and eighty-eight one-day-old male Arbor Acres broiler chicks were randomly assigned using a $2 \times 2$ factorial design into two groups fed either 0 or $500 \mathrm{mg} / \mathrm{kg}$ dietary BLJ and co-challenged (or not challenged for the control) with Eimeria spp./C. perfringens.

Results: Infected birds fed the B $\downarrow$-supplemented diet exhibited an improved feed conversion ratio throughout the trial $(P<0.01)$, a higher villus height and villus height/crypt depth ratio, and reduced intestinal C. perfringens counts, liver $C$. perfringens carriage, gut lesion scores and serum fluorescein isothiocyanate dextran (FITC-D) concentrations at $7 \mathrm{~d}$ postinfection compared with those of birds without $B \sqcup$ supplementation $(P<0.05)$. NE-infected birds fed $\mathrm{B} \sqcup$ exhibited significantly upregulated claudin-1 and IGF-2 mRNA levels $(P<0.05)$, increased A20 mRNA expression and significantly downregulated TRAF-6, TNFSF15 and TOLLIP mRNA levels in the jejunum at $7 \mathrm{~d}$ post-infection compared with those in birds without $B \sqcup$ supplementation $(P<0.05)$. Compared with the uninfected and untreated birds, the uninfected birds fed $B \sqcup$ displayed increased relative abundances of Lactobacillus and Coprococcus but reduced Rikenellaceae levels. Compared with the unsupplemented NE-challenged birds, infected birds fed B $\sqcup$ showed an increased relative abundance of Unclassified_ Lachnospiraceae and a significantly decreased relative abundance of Erysipelotrichaceae.

Conclusion: $\mathrm{B} \sqcup$ supplementation improved growth performance and gut health in NE-infected broiler chickens by strengthening the intestinal barrier function, positively modulating the gut microbiota community and differentially regulating intestinal immune responses. Our results also suggested that adding $B \sqcup$ effectively controlled NE infections after experimental Eimeria and Clostridium perfringens coinfection.
\end{abstract}

Keywords: Broiler chickens, Clostridium perfringens, Essential oils and organic acids, Gut health

\footnotetext{
* Correspondence: wangzh@cau.edu.cn

${ }^{1}$ State Key Laboratory of Animal Nutrition, College of Animal Science and

Technology, China Agricultural University, Beijing 100193, China

Full list of author information is available at the end of the article
}

(c) The Author(s). 2020 Open Access This article is distributed under the terms of the Creative Commons Attribution 4.0 International License (http://creativecommons.org/licenses/by/4.0/), which permits unrestricted use, distribution, and reproduction in any medium, provided you give appropriate credit to the original author(s) and the source, provide a link to the Creative Commons license, and indicate if changes were made. The Creative Commons Public Domain Dedication waiver (http://creativecommons.org/publicdomain/zero/1.0/) applies to the data made available in this article, unless otherwise stated. 


\section{Background}

Necrotic enteritis (NE) due to Clostridium perfringens is an economically important disease in the poultry industry that is characterized by increased mortality, poor bird welfare and huge economic losses as reviewed by Timbermont et al. [1]. In recent decades, in-feed antibiotics were used relatively freely as growth promoters, which helped control NE incidence. However, the ban on using antibiotic growth promoters in poultry feed owing to growing concern about antibiotic-resistant bacteria and the transfer of antibiotic residues in meat and eggs has led to the frequent occurrence of enteric disorders, such as NE [2]. This ban and its consequences have shifted the research focus to exploring effective alternatives to antibiotic growth promoters that can help cost-effectively ameliorate enteric disorders.

Essential oils (EOs) are extracted from plant flowers, leaves, stems, roots, seeds or fruits by steam distillation, extrusion or solvent extraction [3]. The major component of many EOs are phenolic compounds (terpenoids and phenylpropanoids) such as thymol, carvacrol and eugenol [4]. In vitro studies have shown that EOs have antibacterial, antiviral, antifungal, antimycotic, antiparasitic, insecticidal, antioxidant, anti-inflammatory, antitoxigenic, antiquorum-sensing and immune-regulating properties as reviewed in previous reports [5-8]. Thymol and eugenol alter the membrane permeability of microorganisms, causing leakage of intracellular materials. This perturbation in the lipid fraction of the plasma membrane is suggested to generate antimicrobial action [7, 9]. In addition, thymol, eugenol and carvacrol are structurally similar and are reported to exert synergistic or additive antimicrobial effects when supplemented together, even at lower concentrations [4]. The in vitro minimum inhibitory concentration assay showed strong antibacterial activity of the EO product, thymol and carvacrol against pathogenic Escherichia coli, $C$. perfringens and Salmonella strains and weak activity towards beneficial Lactobacillus strains [9]. Therefore, EOs are receiving increasing attention as potential antibiotic growth promotor alternatives in animal production.

Many experiments have indicated that EO supplementation or blends in pig and chicken diets, especially during the grower phase, improved feed palatability and growth performance $[10-20]$, stimulated digestive secretions for improved nutrient digestibility $[20,21]$ and regulated the gut microbiota compositions [21, 22] and lipid metabolism [23]. Additionally, some in vivo trials showed that when animals or poultry were challenged with pathogens, including Salmonella [15], pathogenic E. coli [15] and C. perfringens, or parasites, such as Eimeria spp. [10], EOs also exerted antimicrobial [11], antioxidant, anti-inflammatory [14] and antiparasitic activities, maintained intestinal integrity and strengthened mucosal barrier functions [24].
Organic acids (OAs), such as formic, acetic, propionic, sorbic, hexanoic, benzoic, caprylic and capric acids, are also widely used in livestock as antibiotic alternatives for their ability to improve growth performance, increase endogenous digestive enzyme secretion and activity, improve protein, amino acid and mineral element digestibility [25], benefit intestinal development, improve gut health, maintain the intestinal microecological balance, and exert antimicrobial activity against poultry pathogens such as Escherichia coli [22], Salmonella spp. [22], Campylobacter jejuni [26] and C. perfringens [27]. For example, in broiler chickens, adding coated sodium nbutyrate increased body weight gain and alleviated NEassociated gut injury by upregulating jejunal tight junction protein mRNA levels [28]. Challenged birds given an OAs blend containing formic, acetic, propionic, sorbic, caprylic and capric acids showed improved feed efficiency during the grower stage [29]. Medium-chain fatty acids, such as caproic acids, caprylic acids and capric acid, decrease the numbers of Salmonella in chickens [30, 31] and offer advantages for improving energy supply and performance in piglets, possibly also stabilizing the intestinal microbiota in the post-weaning period [32]. Benzoic acid can enhance the growth performance of weanling pigs by its effect on intestinal tract development [30], nutrient use [31], antioxidative properties and intestinal microbiota [30].

In recent years, the combined use of hydrophobic EOs with lipophilic OAs in broiler diets has been considered the most promising method of substituting antibiotics and has received much attention for the potential synergistic and additive benefits on growth performance and health in pigs and poultry compared with individual EOs or OAs [33]. A blend of OAs and EOs (EOAs) effectively controlled Salmonella in broiler chickens [34]. Adding the EOA mixture (sorbic acid, fumaric acid and thymol) during the grower phase increased efficiency, possibly by improving intestinal morphology and increasing digestive enzyme activities in broiler chickens [35]. Several studies have assessed the interaction effects between EOs and OAs, but these studies have yielded inconsistent results [36]. Sun et al. [18] reported that supplementation with dietary EOs (thymol and carvacrol) and an enzyme complex containing xylanase, glucanase and mannanase benefitted growth performance and gut health in broilers challenged with $C$. perfringens. However, information on the effects of substituting antibiotics with an EOA blend on the gut health of NEinfected broiler chickens is scarce.

BLJ, an EOA blend, is a compound product with $4 \%$ thyme, $4 \%$ carvacrol, $0.5 \%$ hexanoic acid, $3.5 \%$ benzoic acid and $0.5 \%$ butyric acid encapsulated in $\mathrm{Ca}$-alginate and whey protein microcapsules. In vitro studies have demonstrated that encapsulated BLJ retains its antimicrobial activity 
(unpublished data). In addition, microcapsules with an optimized encapsulation formula showed the desired release of the above-mentioned EOs and OAs in a simulated intestinal model and enhanced delivery to the chicken and pig intestines (unpublished data). The present study assessed whether dietary supplementation with BLJ could effectively control NE infections in broiler chickens. The underlying mechanism of action was further investigated by determining the gut microbiota composition, intestinal barrier-related gene expression (claudin-1, ZO-1 and occludin) and intestinal Toll-like receptor (TLR) immune-related gene expression in broiler chickens challenged with NE.

\section{Materials and methods}

\section{Experimental design, birds and diets}

A $2 \times 2$ completely randomized factorial design was used to investigate the effects of two levels of BLJ supplementation $(0$ and $500 \mathrm{mg} / \mathrm{kg}$ of diet) and two levels of NE challenge (NE-challenged or unchallenged). Two hundred and eighty-eight 1-day-old male broiler chicks were purchased from a commercial hatchery (Beijing Arbor Acres Poultry Breeding Company, Beijing, China). Chicks were randomly divided into the four experimental groups, and each group had six replicate pens with 12 birds per pen. The treatment groups were as follows: (i) negative control group (no BLJ supplementation, no NE infection, group A); (ii) BLJ-treated group (BLJ supplementation at 500 $\mathrm{mg} / \mathrm{kg}$ from d 1-42, no NE, group B); (iii) NE-infected control group (no BLJ supplementation, challenged with $\mathrm{NE}$, group D); and (iv) BLJ-treated and NE-infected group (BLJ supplementation at $500 \mathrm{mg} / \mathrm{kg}$ from d 1-42, challenged with NE, group G). The BLJ was provided by Menon Animal Nutrition Technology Co. Ltd., Shanghai, China. To avoid cross-contamination, the uninfected and NE-infected birds were reared in separate areas. In accordance with the AA Broiler Management Guide, all birds received continuous light for the first $24 \mathrm{~h}$ and were then maintained under a 23-h light/1-h dark cycle for the remainder of the study. The temperature in the pen was maintained at $33-34{ }^{\circ} \mathrm{C}$ for the first three days post-hatch, then gradually decreased by $2{ }^{\circ} \mathrm{C}$ per week to a final temperature of $22-24^{\circ} \mathrm{C}$. An antibiotic-free, coccidiostatfree, pelleted basal diet was prepared according to the National Research Council (NRC, 1994) requirements for the starter (d 1-21) and grower (d 22-42) periods. Table 1 presents the basal feed compositions and associated nutrient levels. Birds were provided feed and water ad libitum throughout the trial.

\section{Necrotic enteritis disease model}

NE was induced in broilers as previously described with some modifications [37]. Briefly, birds in the challenged groups were orally gavaged via the crop with Eimeria maxima $\left(1.0 \times 10^{4}\right.$ oocysts/bird $)$ and Eimeria necatrix $\left(5.0 \times 10^{3}\right.$
Table 1 Composition and nutrient levels of the experimental basal diet, on an as-fed basis unless stated otherwise, \%

\begin{tabular}{|c|c|c|}
\hline Items & 1 to $21 \mathrm{~d}$ & 22 to $42 d$ \\
\hline \multicolumn{3}{|l|}{ Composition, \% } \\
\hline Corn (CP 7.8\%) & 39.70 & 57.0 \\
\hline Wheat powder & 0 & 5 \\
\hline Wheat & 19.0 & 0 \\
\hline Soybean meal (CP 46.0\%) & 33.0 & 30.0 \\
\hline Soybean oil & 4.00 & 4.40 \\
\hline Limestone-calcium carbonate & 1.50 & 1.50 \\
\hline Calcium hydrogen phosphate & 1.50 & 1.36 \\
\hline Phytase & 0.02 & 0.03 \\
\hline DL-Methionine, 98\% & 0.27 & 0.19 \\
\hline L-Lysine $\mathrm{HCl}, 78 \%$ & 0.20 & 0.11 \\
\hline Sodium chloride & 0.30 & 0.30 \\
\hline Vitamin premix ${ }^{1}$ & 0.03 & 0.03 \\
\hline Mineral premix ${ }^{2}$ & 0.20 & 0.20 \\
\hline Choline chloride, 50\% & 0.25 & 0.15 \\
\hline Ethoxyquin, 33\% & 0.05 & 0.03 \\
\hline Total & 100 & 100 \\
\hline \multicolumn{3}{|l|}{ Calculated nutrient levels ${ }^{3}$} \\
\hline Metabolizable energy, kcal/kg & 3015.55 & 3101.20 \\
\hline Crude protein, \% & 21.37 & 19.27 \\
\hline Calcium, \% & 0.99 & 0.93 \\
\hline Available phosphorus \% & 0.45 & 0.43 \\
\hline Lysine, \% & 1.20 & 1.05 \\
\hline Methionine, \% & 0.57 & 0.46 \\
\hline Methionine + Cysteine, \% & 0.90 & 0.78 \\
\hline
\end{tabular}

${ }^{1}$ Vitamin premix provided per $\mathrm{kg}$ of complete diet: vitamin $\mathrm{A}$ (retinyl acetate), 12,500 IU; vitamin $\mathrm{D}_{3}$ (cholecalciferol), 2,500 IU; vitamin E ( $D$ L-a-tocopherol acetate), $30 \mathrm{IU}$; vitamin $\mathrm{K}_{3}$ (menadione sodium bisulfate), $2.65 \mathrm{mg}$; vitamin $\mathrm{B}_{12}$ (cyanocobalamin), $0.025 \mathrm{mg}$; biotin, $0.30 \mathrm{mg}$; folic acid, $1.25 \mathrm{mg}$; nicotinic acid, $50 \mathrm{mg}$; $D$-pantothenic acid, $12 \mathrm{mg}$; pyridoxine hydrochloride, $6.0 \mathrm{mg}$; riboflavin, $6.5 \mathrm{mg}$; thiamine mononitrate, $3.0 \mathrm{mg}$

${ }^{2}$ Mineral premix provided per $\mathrm{kg}$ of complete diet: iron, $80 \mathrm{mg}$; copper, $8 \mathrm{mg}$; manganese, $100 \mathrm{mg}$; zinc, $80 \mathrm{mg}$; iodine, $0.35 \mathrm{mg}$; selenium, $0.15 \mathrm{mg}$

${ }^{3}$ Calculated value based on analysis of the experimental diets

oocysts/bird) oocysts (received from Prof. Suoxun, College of Veterinary Medicine, China Agricultural University) on day 14 post-hatch followed by oral gavage with $1 \mathrm{~mL}$ of $C$. perfringens type A CVCC52 (China Veterinary Culture Collection Center, China Institute of Veterinary Drug Control, Beijing, China) at $2.2 \times 10^{8}$ colony-forming units (CFU)/mL per day from d 18-20. Uninfected control birds received 1 $\mathrm{mL}$ of sterile phosphate-buffered saline by oral gavage at the same time-points. Feed was withdrawn $8 \mathrm{~h}$ prior to each inoculation.

\section{Growth performance}

Body weight (BW) and feed intake from each replicate cage were measured on d 1, 21 and 42. Average body 
weight gain (BWG), average feed intake (AFI) and the feed conversion ratios (FCRs) were calculated. Mortality rates were recorded daily.

\section{Intestinal lesion scores and sample collection}

At $7 \mathrm{~d}$ post-infection (DPI; at $28 \mathrm{~d}$ of age) with C. perfringens, one bird per replicate was randomly selected, weighed and euthanized via cervical dislocation. Three independent observers blinded to the study groups scored the NE gut lesions on a scale of 0 (no lesions) to 4 (severe lesions) as previously described [28]. Concurrently, $\sim 1$-cm-long jejunal samples taken from between Meckel's diverticulum and the proximal end of the jejunum were snap-frozen in liquid nitrogen and stored at $-80^{\circ} \mathrm{C}$ for mRNA analysis. Additional $\sim 2$-cm-long jejunal samples, taken midway between the endpoint of the duodenal loop and Meckel's diverticulum, were collected, flushed with $10 \%$ neutral buffered formalin and fixed overnight in $10 \%$ neutral buffered formalin for histological examination. The cecal contents and liver tissues were aseptically collected and immediately frozen at $-40^{\circ} \mathrm{C}$ for bacterial population analysis or bacterial translocation analysis, respectively.

\section{Histomorphological structure and goblet cell analysis of the jejunum}

The gut histomorphology (villus height and crypt depth) and goblet cells were analyzed as previously described [38]. Briefly, the fixed tissue samples were dehydrated in a tissue processor (Leica Microsystems K. K., Tokyo, Japan) and embedded in paraffin wax. Paraffin sections $(5 \mu \mathrm{m})$ were sliced using a microtome (Leica Microsystems K. K., Tokyo, Japan) and mounted on glass slides. The paraffin was removed by xylene (twice for $5 \mathrm{~min}$ each), followed by rehydration in $95 \%$ alcohol $(5 \mathrm{~min})$ and $50 \%$ alcohol $(5 \mathrm{~min}$ ). Sections were stained with hematoxylin and eosin (H\&E) for villous morphology measurement (Leica Microsystems Ltd., Wetzlar, Germany). Goblet cells were visualized by periodic acid-Schiff staining. The area of the goblet cells in different intestinal sections was counted based on the length and width of the goblet cell "cup" in cross-sections of the villi under an Olympus light microscope (Olympus Optical Co., Beijing, China). The density of goblet cells was calculated as the number of goblet cells per unit surface area $\left(\mathrm{mm}^{2}\right)$.

\section{Intestinal permeability analysis by measuring bacterial translocation and serum fluorescein isothiocyanate dextran (FITC-D) concentrations}

C. perfringens cells in the liver were counted using the plate-pouring method as previously described [37]. Bacterial translocation was expressed in CFUs $\left(\log _{10} \mathrm{CFU} / \mathrm{g}\right.$ of tissue). At 7 DPI, all chickens were orally gavaged with FITC-D (3000-5000 Da molecular weight, Sigma
Aldrich, St. Louis, MO, USA) at $8.32 \mathrm{mg} / \mathrm{mL} /$ bird. Blood samples were collected at 1 or $2.5 \mathrm{~h}$ after administering FITC-D, then centrifuged at $3000 \times g$ for $10 \mathrm{~min}$ to separate the serum for FITC-D analysis as previously described [39]. In brief, standard curves $(0,0.0001$, $0.001,0.01,0.1,1.0$ and $10 \mu \mathrm{g} / \mathrm{mL}$ ) were prepared using FITC-D. FITC-D levels in diluted sera (1:5) were measured at excitation and emission wavelengths of $485 \mathrm{~nm}$ and $528 \mathrm{~nm}$, respectively (Synergy HT, multi-mode microplate reader, BioTek Instruments, Inc., VT, USA). The FITC-D concentration per $\mathrm{mL}$ of serum was calculated based on a standard curve.

\section{Real-time polymerase chain reaction (PCR)}

Total RNA was isolated from the snap-frozen jejunal tissue samples $(50 \mathrm{mg})$ with an RNeasy mini kit following the animal tissue protocol (Qiagen, Germantown, MD, USA). The purity and concentration of the total RNA were measured with a spectrophotometer (NanoDrop-2000, Thermo Fisher Scientific, Waltham, MA, USA) using a 260:280-nm absorbance ratio. The absorption ratios $\left(\mathrm{OD}_{260} /\right.$ $\mathrm{OD}_{280}$ ) of all of the samples ranged from 1.8-2.0. First-strand cDNA was synthesized from $2 \mu \mathrm{g}$ of total RNA using a Primer Script ${ }^{\mathrm{Tw}} \mathrm{RT}$ reagent kit with gDNA Eraser (Perfect Real Time; Takara Biotechnology Co. Ltd., Tokyo, Japan) as per the manufacturer's instructions and stored at $-80{ }^{\circ} \mathrm{C}$ until further processing. Quantitative real-time $\mathrm{PCR}$ (qRT-PCR) oligonucleotide primers for the TLR signaling pathway-related genes, tight junction proteins, growth factors, mucin- 2 and $\beta$-actin (Tables 2 and 3) were designed with Primer Express 3.0 (Applied Biosystems, Foster City, CA, USA) and synthesized by Sangon Biotech Co., Ltd. (Shanghai, China). Primers were designed to span introns to avoid genomic DNA amplification. Quantitative real-time PCR was performed using the Applied Biosystems 7500 Fast Real-Time PCR System and a SYBR Premix Ex Taq ${ }^{\text {tix }}$ kit (Takara Biotechnology Co. Ltd., Beijing, China). Reactions were performed in a $20-\mu \mathrm{L}$ volume containing $10.0 \mu \mathrm{L}$ of SYBR Premix Ex Taq $(2 \times)$ mix, $1.0 \mu \mathrm{L}$ of cDNA, $0.5 \mu \mathrm{L}$ of each primer $(10 \mathrm{mM})$ and $8.0 \mu \mathrm{L}$ of sterile nucleasefree water. For the PCR, samples were subjected to an initial denaturation phase at $95^{\circ} \mathrm{C}$ for $5 \mathrm{~min}$, followed by 40 cycles of denaturation at $95^{\circ} \mathrm{C}$ for $30 \mathrm{~s}$ and annealing and extension at $60^{\circ} \mathrm{C}$ for $30 \mathrm{~s}$. Melt curve analysis was performed to confirm the PCR amplification specificity. All tissue samples for cDNA synthesis were analyzed in triplicate. All PCR amplifications were performed in triplicate. Gene expressions were analyzed using $\beta$-actin as an internal control. Average gene expression relative to 
Table 2 Nucleotide sequences of primers (TLR-mediated signaling pathway-related cytokines, chemokines and negative regulators) for quantitative real-time $P C R^{1}$ assay

\begin{tabular}{|c|c|c|c|}
\hline Name & & Primer sequence $\left(5^{\prime} \rightarrow 3^{\prime}\right)$ & GenBank accession \\
\hline \multirow[t]{4}{*}{ Receptors } & $T L R-2$ & F: GGGGCTCACAGGCAAAATC & NM_001161650.1 \\
\hline & & R: AGCAGGGTTCTCAGGTTCACA & \\
\hline & $T L R-4$ & F:CCACTATTCGGTTGGTGGAC & NM_001030693.1 \\
\hline & & R:ACAGCTTCTCAGCAGGCAAT & \\
\hline \multirow[t]{6}{*}{ Adaptor proteins } & MyD88 & F:GGATGGTGGTCGTCATTTCA & NM_001030962.1 \\
\hline & & R:GAGATTTTGCCAGTCTTGTCCA & \\
\hline & TRAF-6 & F: CACAGAGGAGACGCAGGGATA & XM_001235884.1 \\
\hline & & R: AACAGATCGGGCACTCGTATT & \\
\hline & $N F-k B$ & F:TGGAGAAGGCTATGCAGCTT & NM_205134.1 \\
\hline & & R:CATCCTGGACAGCAGTGAGA & \\
\hline \multirow[t]{8}{*}{ Pro-inflammatory cytokines } & TNFSF15 & F- CCAAGAGCACACCTGACAGT & NM_001024578.1 \\
\hline & & R- CACAGGTATCACCAGTGCGT & \\
\hline & $\mathbb{L L}-1 \beta$ & F-CAGCAGCCTCAGCGAAGAG & NM_204524.1 \\
\hline & & R-CTGTGGTGTGCTCAGAATCCA & \\
\hline & $\operatorname{LL}-8$ & F-GGCTTGCTAGGGGAAATGA & AJ009800 \\
\hline & & R-AGCTGACTCTGACTAGGAAACTGT & \\
\hline & $I F N-\gamma$ & F-AAAGCCGCACATCAAACACA & NM_205149.1 \\
\hline & & R-GCCATCAGGAAGGTTGTTTTC & \\
\hline \multirow[t]{2}{*}{ Ant-inflammatory cytokines } & $\operatorname{lL}-10$ & F:CGCTGTCACCGCTTCTTCA & NM_001004414.2 \\
\hline & & R:CGTCTCCTTGATCTGCTTGATG & \\
\hline \multirow[t]{10}{*}{ Negative regulators } & Tollip & F:CATGGTACCTGTGGCAATACC & NM_001006471 \\
\hline & & R:GCACTGAGCGGATTACTTCC & \\
\hline & PI3K & F:AACATCTGGCAAAACCAAGG & NM_001004410 \\
\hline & & R:CTGCAATGCTCCCTITAAGC & \\
\hline & A2O & $\mathrm{F}: G A G A A C G C A G A G C C T A C A C C$ & NM_001277522.1 \\
\hline & & R:CCAACCTTCTTCCTGCACAT & \\
\hline & SOCS-1 & F:GCTCTCAGGCTCGAGGTTAC & NM_001137648.1 \\
\hline & & R:GCTTGCTCGAGTGATGCTACT & \\
\hline & SOCS-6 & F: CAGATATCTTTGTGGACCAGGCAGTGAA & NM_001127312 \\
\hline & & R: GGTAGCAAAGGTGAAAGTGGAGGGACATC & \\
\hline
\end{tabular}

'Primers were designed and synthesized by Sango Biotech (Shanghai) Co., Ltd. F: forward; R: reverse

$T L R$ Toll-like receptor; MyD88 myeloid differential protein-88; TRAF-6 TNF receptor-associated factor 6 ; NF-KB nuclear factor kappa-light-chain-enhancer of activated B cells; TNFSF15 tumor necrosis factor superfamily member 15; IL interleukin; IFN- $\gamma$ interferon $\gamma$; Tollip Toll-interacting protein; PI3K phosphatidylinositol 3-kinase;

A2O protein A20; SOCS suppressor of cytokine signaling

the $\beta$-actin internal control for each sample was calculated using the $2^{-\Delta \Delta \mathrm{Ct}}$ method [40].

\section{Microbiota DNA extraction, 16S rRNA amplification, sequencing and sequence data processing}

Microbial genomic DNA was extracted from cecal content samples using the QIAamp Fast DNA stool mini kit (Qiagen, Mannheim, Germany) following the manufacturer's instructions. The quantity and quality of the extracted DNA were measured using a NanoDrop ND1000 spectrophotometer (Thermo Fisher Scientific) and agarose gel electrophoresis, respectively, then the genomic DNA was used as a template for PCR amplification. The bacterial 16S RNA V3-V4 gene region was amplified using the KAPA HiFi Hotstart Ready Mix PCR kit (Kapa Biosystems, Wilmington, Massachusetts, USA) and primers F341 and R806 (F341: 5' ${ }^{\prime}$-ACTCCT ACGGGAGGCAGCA-3', R806: 5'-GGACTACH VGGGTWTCTAAT- $3^{\prime}$ ). The PCR conditions were as follows: initial pre-denaturation at $94^{\circ} \mathrm{C}$ for $5 \mathrm{~min}, 30 \mathrm{cy}$ cles of denaturation at $95^{\circ} \mathrm{C}$ for $30 \mathrm{~s}$, annealing at $50^{\circ} \mathrm{C}$ for $30 \mathrm{~s}$, elongation at $72^{\circ} \mathrm{C}$ for $30 \mathrm{~s}$ and a final elongation at $72{ }^{\circ} \mathrm{C}$ for $5 \mathrm{~min}$. The amplicons were examined via $2 \%$ agarose gel electrophoresis, and the target 
Table 3 Nucleotide sequences of primers (tight junction proteins and growth factors) for quantitative real-time PCR ${ }^{1}$ assay

\begin{tabular}{|c|c|c|}
\hline Name & Primer sequence $\left(5^{\prime} \rightarrow 3^{\prime}\right)$ & GenBank accession \\
\hline \multicolumn{3}{|c|}{ Tight junctions } \\
\hline \multirow[t]{2}{*}{ Claudin-1 } & F: AAGTGCATGGAGGATGACCA & NM_001013611.2 \\
\hline & R: GCCACTCTGTTGCCATACCA & \\
\hline \multirow[t]{2}{*}{ Occludin } & F:TCATCGCCTCCATCGTCTAC & NM_205128.1 \\
\hline & R:TCTTACTGCGCGTCTTCTGG & \\
\hline \multirow[t]{2}{*}{ ZO-1 } & F: TATGAAGATCGTGCGCCTCC & XM_015278981.1 \\
\hline & R: GAGGTCTGCCATCGTAGCTC & \\
\hline \multirow[t]{2}{*}{ Mucin-2 } & F: AGCGAGATGTTGGCGATGAT & NM_001318434.1 \\
\hline & R: AAGTTGCCACACAGACCACA & \\
\hline \multicolumn{3}{|c|}{ Growth factors } \\
\hline \multirow[t]{2}{*}{ TGF- $\beta 3$} & F:TGCGGCCAGATGAGCAT & NM_205454.1 \\
\hline & R:TGCACATTCCTGCCACTGA & \\
\hline \multirow[t]{2}{*}{ IGF-2 } & F: TGGCTCTGCTGGAAACCTAC & NM_001030342.2 \\
\hline & R: ACTTGGCATGAGATGGCTTC & \\
\hline \multirow[t]{2}{*}{ EGFR } & F: ACCAGCCTGCAGAGAATGTA & NM_205497 \\
\hline & R: CACCATGTTAAGCGCAATGA & \\
\hline \multirow[t]{2}{*}{ GLP-2 } & F:AAGCTTCCCAGTCTGAACCA & NM_205260.4 \\
\hline & R:ATCCTGAGCTCGTCTGCTGT & \\
\hline \multicolumn{3}{|c|}{ House-keeping genes } \\
\hline \multirow[t]{2}{*}{$\beta$-actin } & F: GAGAAATTGTGCGTGACATCA & NM 205518 \\
\hline & R: CCTGAACCTCTCATTGCCA & \\
\hline
\end{tabular}

'Primers were designed and synthesized by Sango Biotech (Shanghai) Co., Ltd. F: forward; R: reverse

ZO-1 zonula occludens-1; EGFR epidermal growth factor receptor; GLP-2 glucagon-like peptide-2; IGF-2 insulin-like growth factor-2; TGF- $\beta 3$

transforming growth factor beta 3

fragment was excised and subsequently purified using a QIA quick Gel Extraction Kit (Qiagen, USA). Finally, 16S rRNA gene sequencing was performed using the Illumina MiSeq PE250 platform (Illumina, Santa Clara, CA, USA) with the MiSeq Reagent Kit at Shanghai Personal Biotechnology Co., Ltd. (Shanghai, China).

The raw sequence data obtained from the Illumina MiSeq platform were quality-filtered and demultiplexed using Quantitative Insights into Microbial Ecology (QIIME), version 1.8.0-dev (http://qiime.org/index.html). Sequences with an average Phred score lower than 20, containing ambiguous bases, homopolymer runs exceeding six, mismatched primers or sequence lengths shorter than $150 \mathrm{bp}$ were removed. Only sequences with an overlap longer than $10 \mathrm{bp}$ and with no mismatches were assembled according to their overlap sequence using FLASH [41]. Reads that could not be assembled were discarded. Barcode and sequencing primers were trimmed from the assembled sequence. Trimmed sequences were uploaded to QIIME for further analysis. The trimmed and assembled sequences from each sample were aligned to the Greengenes $16 \mathrm{~S}$ rRNA training set 10 using the best hit classification option to classify the taxonomic abundance in QIIME [42]. Bacterial operational taxonomic units (OTUs) were generated using the UCLUST function in QIIME (http://qiime.org/ scripts/pick_otus) with a $97 \%$ similarity threshold. The alpha diversity measures, including the observed OTUs/ read and the abundance-based coverage (ACE), Chao 1, Good's coverage, Shannon and Simpson indices were calculated using MOTHUR. Beta diversity analysis was performed to investigate the structural variation of microbial communities across samples using UniFrac distance metrics [43]. Differences in the UniFrac distances for pairwise comparisons among groups were determined using the Student's t-test and Monte Carlo permutation test with 1000 permutations and were visualized through box-and-whisker plots. Principal component analysis was conducted based on the genuslevel compositional profiles [44]. A Venn diagram was generated to visualize the shared and unique OTUs among samples or groups using the $\mathrm{R}$ package, "Venn Diagram", based on OTU occurrence across samples/ groups regardless of their relative abundances [45]. Partial least squares discriminant analysis (PLS-DA) was also introduced as a supervised model to reveal the microbiota variation among groups using the "PLS-DA" function in the R package, "mix Omics" [46]. Significant differences between the microbiota compositions in the control and BLJ-treated chickens were determined via a nonparametric Mann-Whitney U test ranked using the percentage of representation of individual genera.

\section{Statistical analysis}

Data regarding growth performance, gut lesion scores, intestinal bacterial concentrations, liver C. perfringens, jejunum morphology, goblet cell numbers, intestinal permeability, relative mRNA expression levels and the Shannon and ACE alpha diversity indices among the four groups were analyzed using one-way ANOVA in SPSS 20.0 (SPSS Inc., Chicago, IL, USA) in a $2 \times 2$ factorial design. Mean separations were conducted using Duncan's multiple comparison when interactive effects differed significantly. Phylum and genus abundances were compared using the Kruskal-Wallis test with Benjamini-Hochberg $P$-value correction. $P \leq 0.05$ was considered significant, and $0.05 \leq P \leq 0.10$ was considered a trend.

\section{Results}

\section{Growth performance}

Table 4 presents the growth performance results for the broiler chickens. Compared with the unchallenged groups, the untreated NE-challenged group had significantly decreased BWG on d 1 to 21 and d 1 to 42, and AFI from $d 1$ to 21 , and notably increased FCR at the 
Table 4 Effect of BLJ on growth performance of broiler chickens challenged with NE

\begin{tabular}{|c|c|c|c|c|c|c|c|c|c|c|c|c|}
\hline \multicolumn{5}{|c|}{ Itexpserimental design } & \multicolumn{5}{|c|}{ SEMMLin effect } & \multicolumn{3}{|l|}{$P$-value ${ }^{6}$} \\
\hline & $A^{1}$ & $\mathrm{D}^{2}$ & $\mathrm{~B}^{3}$ & $\mathrm{G}^{4}$ & & 0 & 500 & Non-challenge & Challenged & Treatment & Challenged & $T \times C$ \\
\hline \multicolumn{13}{|l|}{ d 1 to 21} \\
\hline $\begin{array}{l}\text { BWG, g/ } \\
\text { bird }\end{array}$ & 870 & 655 & 857 & 647 & 21.40 & 763 & 752 & $864^{\mathrm{a}}$ & $651^{b}$ & 0.449 & $<0.01$ & 0.843 \\
\hline AFI, g/bird & 1249 & 1047 & 1246 & 1057 & 20.14 & 1148 & 1151 & $1248^{a}$ & $1052^{\mathrm{b}}$ & 0.842 & $<0.01$ & 0.676 \\
\hline$F C R, g / g$ & 1.44 & 1.60 & 1.45 & 1.64 & 0.02 & 1.52 & 1.55 & $1.44^{\mathrm{b}}$ & $1.62^{\mathrm{a}}$ & 0.085 & $<0.01$ & 0.533 \\
\hline \multicolumn{13}{|l|}{ d 22-42 } \\
\hline $\begin{array}{l}\text { BWG, g/ } \\
\text { bird }\end{array}$ & 1904 & 1891 & 1883 & 1919 & 29.59 & 1898 & 1901 & 1894 & 1905 & 0.955 & 0.844 & 0.681 \\
\hline AFI, g/bird & $3095^{\mathrm{a}}$ & $3114^{\mathrm{a}}$ & $2684^{b}$ & $3083^{\mathrm{a}}$ & 39.40 & 3104 & 2883 & 2890 & 3098 & 0.010 & 0.015 & 0.025 \\
\hline$F C R, g / g$ & $1.63^{\mathrm{a}}$ & $1.65^{\mathrm{a}}$ & $1.43^{b}$ & $1.60^{\mathrm{a}}$ & 0.01 & 1.64 & 1.51 & 1.53 & 1.62 & $<0.01$ & $<0.01$ & $\begin{array}{l}< \\
0.01\end{array}$ \\
\hline \multicolumn{13}{|l|}{ d 1 to 42} \\
\hline $\begin{array}{l}\text { BWG, g/ } \\
\text { bird }\end{array}$ & 2774 & 2546 & 2740 & 2566 & 34.08 & 2660 & 2653 & $2757^{\mathrm{a}}$ & $2556^{\mathrm{b}}$ & 0.918 & 0.008 & 0.696 \\
\hline AFI, g/bird & 4344 & 4161 & 3931 & 4140 & 55.89 & $4252^{a}$ & $4035^{b}$ & 4137 & 4151 & 0.033 & 0.890 & 0.050 \\
\hline$F C R, g / g$ & $1.54^{b}$ & $1.63^{\mathrm{a}}$ & $1.44^{c}$ & $1.62^{\mathrm{a}}$ & 0.01 & 1.59 & 1.53 & 1.50 & 1.63 & $<0.01$ & $<0.01$ & $\begin{array}{l}< \\
0.01\end{array}$ \\
\hline
\end{tabular}

${ }_{\mathrm{a}, \mathrm{b}}$ Means within the same row without a common superscript differ significantly $(P<0.05)$

${ }^{1} A$ neither BLJ treatment nor NE infection

${ }^{2} D$ NE infection but without BLJ treatment

${ }^{3} B$ BLJ treatment at $500 \mathrm{mg} / \mathrm{kg}$ of feed but without NE infection

${ }^{4} G$ both $B L J$ treatment and NE infection

${ }^{5} S E M$ standard error of the mean

${ }^{6} P$-values represent the main effect of the diet, the main effect of the NE challenge, and the interaction between the dietary treatments and NE challenge; BWG: body weight gain, g/bird; AFI: average feed intake, g/bird; FCR: feed conversion ratio, $g$ of feed intake/g of BW gain, g/g; T×C: treatment and challenged

different stages $(P<0.01)$. Dietary supplementation with BLJ resulted in a notable improvement in FCR $(P<$ $0.01)$, whereas a significantly reduced AFI $(P<0.05)$ at the later and whole trial stage compared with the unsupplemented group.

A notable interaction was observed for FCR and AFI during d 22 to 42 and over the whole period between BLJ administration and NE challenge. Non-infected birds fed BLJ displayed a significant reduction in AFI $(P \leq 0.05)$ and a remarkable improvement in FCR $(P<0.01)$ compared with the single NE-challenged control and other treatments.

\section{Intestinal lesion scores and morphological observations}

$\mathrm{NE}$ infection significantly increased the jejunum crypt depth $(P<0.01)$ and the small intestinal lesion scores $(P<0.05)$, reduced the villus height $(P=0.076)$ and remarkably decreased the VH/CD ratio in the jejunums of the NE-challenged birds compared with those of the uninfected birds (Table 5). In addition, chickens who received BLJ diets had greater villus height $(P<0.05)$ and $\mathrm{VH} / \mathrm{CD}$ ratios $(P<0.01)$ in the jejunum compared with those of the unsupplemented groups (Table 5). Infected birds fed diets with BLJ also displayed lower gut lesion scores $(P<0.05)$ in the small intestines at 7 DPI $(\mathrm{d} 28)$ than those of the untreated NE-infected birds, and lower crypt depths $(P<0.05)$ compared with those of birds that did not receive BLJ-supplemented diets. The interaction between BLJ supplementation and NE infection had a combined effect on the small intestinal lesion score, crypt depth and VH/CD ratio at d 28 (7 DPI). NE-infected birds fed diets supplemented with BLJ exhibited significantly decreased gut lesion scores and crypt depths $(P<0.05)$ and a notably increased $(\mathrm{VH} / \mathrm{CD})$ ratio $(P<0.05)$ in the small intestine at 7 DPI compared with those of the single NE-infected birds. However, jejunal goblet cells (on d 28) did not significantly differ among the groups.

\section{Liver C. perfringens invasion and serum FITC-D levels}

A significant interaction effect occurred between liver $C$. perfringens invasion and cecal $C$. perfringens colonization between the NE-infected and BLJ-supplemented groups (Table 6). Challenged birds fed diets supplemented with BLJ showed significantly fewer $C$. perfringens $(P<0.05)$ in the liver and cecal contents throughout the infection period compared with those in the NE-infected birds. The number of $C$. perfringens in the liver and cecum of the NE-infected birds at 7 DPI notably increased $(P<0.01)$ compared with those of the uninfected birds. Conversely, the $C$. perfringens populations in the livers and ceca of the BLJ-treated birds at 7 DPI decreased significantly $(P<0.01)$ compared with those of the unsupplemented group. The interaction between BLJ supplementation and NE infection had a 
Table 5 Effect of dietary BLJ supplementation on jejunal lesion scores, morphology and goblet cell numbers in broiler chickens challenged with NE at $28 \mathrm{~d}$ of age

\begin{tabular}{|c|c|c|c|c|c|c|}
\hline Items & $N E^{1}$ & Jejunum lesion scores & Villous height, $\mu \mathrm{m}$ & Crypt depth, $\mu \mathrm{m}$ & $\mathrm{VH} / \mathrm{CD}^{2}$ & $\mathrm{GC}^{3}$ cells \\
\hline \multicolumn{7}{|l|}{$\mathrm{BLJ}, \mathrm{mg} / \mathrm{kg}$} \\
\hline 0 & - & $0.14^{c}$ & 439.66 & $61.93^{b}$ & $7.07^{b}$ & 23.57 \\
\hline 0 & + & $1.33^{\mathrm{a}}$ & 398.69 & $112.52^{\mathrm{a}}$ & $3.56^{\mathrm{c}}$ & 17.23 \\
\hline 500 & - & $0.29^{b c}$ & 507.07 & $59.00^{\mathrm{b}}$ & $8.66^{\mathrm{a}}$ & 23.03 \\
\hline 500 & + & $0.58^{\mathrm{b}}$ & 446.39 & $66.69^{b}$ & $6.75^{b}$ & 23.87 \\
\hline $\mathrm{SEM}^{4}$ & & 0.07 & 15.00 & 4.91 & 0.41 & 1.06 \\
\hline \multicolumn{7}{|l|}{ Main effect } \\
\hline 0 & & 0.74 & $419.18^{\mathrm{b}}$ & 87.22 & 5.31 & 20.40 \\
\hline 500 & & 0.43 & $476.73^{a}$ & 62.85 & 7.70 & 23.45 \\
\hline Non-challenged & & 0.21 & 473.37 & 60.47 & 7.86 & 23.30 \\
\hline Challenged & & 0.96 & 422.54 & 89.60 & 5.15 & 20.55 \\
\hline \multicolumn{7}{|l|}{$P$-value ${ }^{5}$} \\
\hline$B\llcorner J$ & & 0.043 & 0.046 & $<0.01$ & $<0.01$ & 0.130 \\
\hline Challenged & & $<0.01$ & 0.076 & $<0.01$ & $<0.01$ & 0.170 \\
\hline Challenged×BLJ & & $<0.01$ & 0.720 & $<0.01$ & 0.011 & 0.078 \\
\hline
\end{tabular}

a, b, cMeans within the same column with different superscripts differ significantly $(P<0.05)$

${ }^{1} N E$ Co-challenged with Eimeria spp. and Clostridium perfringens; -, without NE challenge; + , with NE challenge

${ }^{2} \mathrm{VH} / \mathrm{CD}$ villus height/crypt depth ratio

${ }^{3} \mathrm{GC}$ cells goblet cell numbers per $\mathrm{mm}^{2}$

${ }^{4} S E M$ standard error of the mean

${ }^{5} P$-values represent the main effect of the diet, the main effect of the NE challenge, and the interaction between the dietary treatments and NE challenge

combined effect on the serum FITC-D concentration at $1 \mathrm{~h}$ post-FITC-D gavage (Table 6). Compared with NE-infected birds and the untreated groups, the infected and uninfected birds fed BLJ exhibited lower serum FITC-D concentrations at $1 \mathrm{~h}$ post-FITC-D gavage $(P<0.05)$ but no significant effect was observed on the serum FITC-D concentration at $2.5 \mathrm{~h}$ post-FITC-D gavage.

\section{Expression of the intestinal tight junction and mucin-2 genes}

Table 7 shows the changes in tight junction, mucin-2 and growth factor mRNA expression in the jejunum. Based on the main-effect NE challenge, NE infection notably downregulated occludin, zonula occludens-1 (ZO-1), epithelial cell growth factor receptor (EGFR) and mucin-2 mRNA levels and remarkably upregulated GLP2 and IGF-2 mRNA levels in the jejunum $(P<0.05)$ compared with those in the unchallenged groups $(P<$ 0.05). Conversely, BLJ-treated birds showed lower $\mathrm{ZO}-1$ and higher IGF-2 and GLP-2 expression levels in the jejunum than those in the unsupplemented controls. In addition, a significant interaction effect on claudin-1, IGF-2 and mucin-2 mRNA expressions occurred between NE infection and BLJ addition. Challenged birds fed diets supplemented with BLJ showed significantly higher claudin-1 and IGF-2 mRNA levels $(P<0.05)$ in the jejunum at 7 DPI compared with those in the NE- infected birds. In addition, uninfected birds fed BLJsupplemented diets showed the highest levels of mucin2 gene expression in the jejunum compared with those of the other three treatments.

\section{mRNA levels of TLR signaling-related cytokines and growth factors in the jejunum}

NE infection significantly downregulated the TLR-4, TRAF-6, NF-KB, TNFSF15, TOLLIP, PI3K and SOCS-6 mRNA levels $(P<0.05)$ and remarkably upregulated IFN$\gamma$ mRNA levels in the jejunum $(P<0.05)$ compared with those of the unchallenged groups (Table 8). The infected birds fed BLJ exhibited lower TLR-4 and TRAF- 6 mRNA levels $(P<0.05)$, increased $A 20$ mRNA levels $(0.05<P<$ $0.10)$ and decreased $I L-1 \beta$ gene expression levels $(0.05<P<0.10)$ compared with the unsupplemented groups. A dramatic interaction effect $(P<0.05)$ on $T L R-2$, TRAF-6, TNFSF15, TOLLIP and SOCS-6 mRNA levels $(P<0.05)$ occurred between NE infection and BLJ addition. NE-infected birds fed diets supplemented with BLJ also exhibited significantly decreased TRAF-6, TNFSF15 and TOLLIP gene expression levels and a decreasing trend was observed in the TLR-2 mRNA level in the jejunum at 7 DPI compared with that in the uninfected birds. In addition, the uninfected birds fed BLJ had the highest SOCS-6 gene expression levels in the jejunum at 7 DPI compared with those of the other three groups. 
Table 6 Effects of dietary supplementation with BLJ on serum FITC-D concentration and cecal and liver Clostridium perfringens (CFU/g) numbers in broiler chickens challenged with NE

\begin{tabular}{lllll}
\hline Items & $\mathrm{NE}^{1}$ & $\mathrm{FITC}-\mathrm{D}, \mathrm{ng} / \mathrm{mL}$ & $\begin{array}{l}\text { Liver } \\
\text { Clostridium } \\
\text { perfringens, } \\
\text { CFU/g }\end{array}$ & $\begin{array}{l}\text { Cecal } \\
\text { Clostridium } \\
\text { perfringens, } \\
\text { CFU/g }\end{array}$ \\
\end{tabular}

\begin{tabular}{llllll}
\hline BLJ, mg/kg & & & & & \\
0 & - & $9.74^{\mathrm{ab}}$ & 9.84 & $0.32^{\mathrm{b}}$ & $0.00^{\mathrm{c}}$ \\
0 & + & $9.88^{\mathrm{a}}$ & 10.00 & $1.93^{\mathrm{a}}$ & $4.69^{\mathrm{a}}$ \\
500 & - & $9.68^{\mathrm{bc}}$ & 9.88 & $0.00^{\mathrm{b}}$ & $0.00^{\mathrm{c}}$ \\
500 & + & $9.52^{\mathrm{c}}$ & 9.83 & $0.42^{\mathrm{b}}$ & $2.23^{\mathrm{b}}$ \\
SEM $^{2}$ & & 0.04 & 0.05 & 0.18 & 0.40 \\
Main effect & & & & & \\
0 & & 9.81 & 9.92 & 1.13 & 2.34 \\
500 & 9.60 & 9.86 & 0.21 & 1.11 \\
Non-challenged & & 9.71 & 9.86 & 0.16 & 0.00 \\
Challenged & 9.70 & 9.92 & 1.18 & 3.46 \\
P-value & & & & \\
BLJ & & & & & $<0.01$ \\
Challenged $_{\text {ChallengedxBLJ }}$ & & 0.838 & 0.570 & $<0.01$ & $<0.01$ \\
\hline
\end{tabular}

a, b, c Means within the same column with different superscripts differ significantly $(P<0.05)$

${ }^{1} \mathrm{NE}$ Co-challenged with Eimeria spp. and Clostridium perfringens; -, without

NE challenge; + , with NE challenge

${ }^{2}$ SEM, standard error of the mean

${ }^{3} P$-values represent the main effect of the diet, the main effect of the NE challenge, and the interaction between the dietary treatments and NE challenge

\section{Cecal microbiome}

To study the effect of the BLJ on the gut microbiotas of broiler chickens infected with NE, the cecal contents of the microbiome were analyzed via deep sequencing. In this study, 769274 effective and high-quality sequences were obtained from all samples $(n=24)$ after processing and filtering. The average coverage of each sample was 45685 (range, 34585-91303) reads. These OTUs were generated and characterized for different taxonomic levels, including phylum and genus, as per the Greengenes database using QIIME. A Venn diagram of the OTU numbers indicated 1776 common core OTUs for all groups and 209, 309, 382 and 235 unique OTUs for the four groups (Fig. 1). Alpha diversity measured using the ACE, Chao1, Simpson and Shannon indices showed that community richness and diversity for the cecal feces did not differ $(P>0.05$; Table 9$)$ among the groups, indicating that NE infection, BLJ treatment or their combination did not alter the alpha diversity of the cecal microbial diversity. Principal component analysis revealed that individuals from each group appeared to be interspersed (Fig. 2), indicating significant variability in the cecal microbiota composition and structure between these groups. Whereas PLS-DA scores for the cecal microbiota showed that the microbial communities were distinctly separated between the untreated NE-infected birds and the NE-infected BLJ-treated birds (Fig. 3).

To investigate the impacts of BLJ supplementation on the cecal microbial compositions of the NE-challenged birds, we compared the variation in bacterial taxa between the $A$ and $B$ and the $D$ and $G$ groups. Phylum level analysis demonstrated that NE infection, BLJ treatment and their combination $(P<0.05)$ influenced the percentages of Firmicutes and Bacteroidetes but not the relative abundances of Proteobacteria, Actinobacteria or other bacterial phyla on d 28 (Fig. 4). However, under the unchallenged conditions, BLJ addition exhibited an increased Firmicutes abundance $(P=0.055)$ and a reduction in Bacteroidetes $(P=0.078)$. For the NE-challenged birds, those fed BLJ did not differ significantly in the relative abundances of phyla. At the genus level, compared with the uninfected and untreated birds, the uninfected birds fed BLJ displayed increased relative distributions of Lactobacillus $(P=0.081)$ and Coprococcus $(P=0.007)$ but decreased Rikenellaceae $(P=0.078)$ levels (Fig. 5). For the NE-challenged birds, infected birds fed BLJ showed increased relative abundances of Unclassified_Lachnospiraceae $(P=0.109)$ and significantly decreased relative abundances of Erysipelotrichaceae $(P=0.031)$.

\section{Discussion}

In the present study, NE challenge decreased the BWG and AFI and increased the feed/gain ratio in chicks fed a basal diet during the infection period, which is consistent with the results reported by Song et al. [28] and Wu et al. [37]. Birds fed a commercial blend of thyme, carvacrol and organic acids (BLJ) showed improved FCR and decreased AFI but no statistical differences in BWG regardless of NE infection. Our results indicated that feeding with BLJ could positively improve FCR in broilers. Consistent with our findings, several recent studies documented that EOA improved the growth performance and/or feed utilization in broilers $[47,48]$ and turkeys [49]. Conversely, other studies suggested that the blend of EOs and sodium butyrate yielded no significant difference in growth performance [50]. These inconsistencies in the efficacy of the EOAs on growth performance may be related to differences in the composition and inclusion levels used, diet type, environmental conditions, animal age, breed and hygienic conditions between studies [3]. Poor hygienic conditions may help the EOs to favorably affect the growth performance and feed efficiency of broilers [51].

Intestinal morphology, including villus height, crypt depth and the VH/CD ratio, is an important indicator of intestinal health, recovery and functionality and plays a 
Table 7 Effects of dietary supplementation with BLJ on gene expressions of tight junction proteins, growth factors and mucin-2 in the jejunums of broiler chickens challenged with NE (at 7 days after NE infection)

\begin{tabular}{|c|c|c|c|c|c|c|c|c|c|}
\hline Items & $\mathrm{NE}^{1}$ & Claudin1 & Occludin & ZO-1 & $T G F-\beta 3$ & IGF-2 & EGFR & $G L P-2$ & Mucin-2 \\
\hline \multicolumn{10}{|l|}{$\mathrm{B}\llcorner J, \mathrm{mg} / \mathrm{kg}$} \\
\hline 0 & - & $0.82^{b}$ & 1.02 & 1.07 & 1.03 & $1.04^{b}$ & 1.02 & 1.04 & $1.05^{b}$ \\
\hline 0 & + & $0.56^{\mathrm{b}}$ & 0.93 & 0.66 & 0.89 & $1.34^{b}$ & 0.86 & 1.05 & $0.71^{c}$ \\
\hline 500 & - & $0.50^{b}$ & 1.10 & 0.64 & 1.18 & $1.21^{\mathrm{b}}$ & 1.45 & 1.26 & $1.44^{\mathrm{a}}$ \\
\hline 500 & + & $1.02^{\mathrm{a}}$ & 0.57 & 0.21 & 1.17 & $2.47^{\mathrm{a}}$ & 0.60 & 1.84 & $0.55^{\mathrm{c}}$ \\
\hline $\mathrm{SEM}^{2}$ & & 0.08 & 0.08 & 0.08 & 0.08 & 0.14 & 0.11 & 0.10 & 0.09 \\
\hline \multicolumn{10}{|l|}{ Main effect } \\
\hline 0 & & 0.69 & 0.98 & $0.87^{\mathrm{a}}$ & 0.96 & 1.19 & 0.94 & $1.05^{\mathrm{b}}$ & 0.88 \\
\hline 500 & & 0.76 & 0.83 & $0.43^{b}$ & 1.17 & 1.84 & 1.03 & $1.55^{\mathrm{a}}$ & 1.00 \\
\hline Non-challenged & & 0.66 & $1.06^{\mathrm{a}}$ & $0.86^{\mathrm{a}}$ & 1.10 & 1.13 & $1.24^{\mathrm{a}}$ & 1.15 & 1.23 \\
\hline Challenged & & 0.79 & $0.57^{b}$ & $0.44^{\mathrm{b}}$ & 1.03 & 1.90 & $0.73^{b}$ & 1.45 & 0.63 \\
\hline \multicolumn{10}{|l|}{$P$-value ${ }^{3}$} \\
\hline BLJ & & 0.592 & 0.310 & $<0.01$ & 0.194 & $<0.01$ & 0.669 & 0.003 & 0.322 \\
\hline Challenged & & 0.335 & 0.034 & $<0.01$ & 0.655 & $<0.01$ & 0.017 & 0.056 & $<0.01$ \\
\hline Challenged×BLJ & & 0.010 & 0.109 & 0.929 & 0.667 & $<0.01$ & 0.094 & 0.064 & 0.027 \\
\hline
\end{tabular}

$\mathrm{a}, \mathrm{b}, \mathrm{c}$ Means within the same column with different superscripts differ significantly $(P<0.05)$

${ }^{1}$ NE Co-challenged with Eimeria spp. and Clostridium perfringens; - , without NE challenge; +, with NE challenge

${ }^{2} S E M$, standard error of the mean

${ }^{3} P$-values represent the main effect of the diet, the main effect of the NE challenge, and the interaction between the dietary treatments and NE challenge

Table 8 Effects of dietary supplementation with BLJ on gene expressions of proinflammatory cytokines, chemokines and TLR signaling pathway-related genes in the jejunums of broiler chickens challenged with NE (at $7 \mathrm{~d}$ after NE infection)

\begin{tabular}{|c|c|c|c|c|c|c|c|c|c|c|c|c|c|c|c|c|}
\hline Items & $N E^{1}$ & $T L R-2$ & $T L R-4$ & MyD88 & TRAF-6 & $N F-k B$ & $I F N-\gamma$ & TNFSF15 & $I L-1 \beta$ & IL-8 & IL-10 & Tollip & PI3K & $A 20$ & SOCS-1 & SOCS-6 \\
\hline \multicolumn{17}{|l|}{$\mathrm{BL}, \mathrm{mg} / \mathrm{kg}$} \\
\hline 0 & - & $1.01^{\mathrm{ab}}$ & 1.66 & 1.02 & $1.02^{\mathrm{a}}$ & 1.06 & 1.01 & $1.00^{\mathrm{bc}}$ & 1.05 & 1.38 & 1.07 & $1.02^{\mathrm{ab}}$ & 1.04 & 1.10 & 1.06 & $1.02^{\mathrm{ab}}$ \\
\hline 0 & + & $1.26^{\mathrm{ab}}$ & 0.88 & 1.01 & $0.96^{\mathrm{ac}}$ & 0.90 & 3.89 & $1.08^{\mathrm{b}}$ & 1.14 & 0.63 & 1.37 & $0.84^{b}$ & 0.73 & 0.93 & 1.23 & $0.92^{\mathrm{b}}$ \\
\hline 500 & - & $1.45^{\mathrm{a}}$ & 0.59 & 1.11 & $1.13^{\mathrm{a}}$ & 1.16 & 1.13 & $1.32^{\mathrm{a}}$ & 1.02 & 0.75 & 0.81 & $1.16^{\mathrm{a}}$ & 1.26 & 1.35 & 1.07 & $1.45^{\mathrm{a}}$ \\
\hline 500 & + & $0.91^{b}$ & 0.46 & 0.87 & $0.36^{\mathrm{b}}$ & 0.39 & 3.13 & $0.79^{c}$ & 0.62 & 1.02 & 1.24 & $0.57^{c}$ & 0.73 & 1.70 & 1.19 & $0.67^{b}$ \\
\hline $\mathrm{SEM}^{2}$ & & 0.08 & 0.13 & 0.04 & 0.08 & 0.10 & 0.34 & 0.05 & 0.08 & 0.14 & 0.11 & 0.06 & 0.07 & 0.14 & 0.11 & 0.09 \\
\hline \multicolumn{17}{|l|}{ Main effect } \\
\hline 0 & & 1.14 & $1.27^{\mathrm{a}}$ & 1.02 & 0.99 & 0.98 & 2.45 & 1.04 & 1.10 & 1.01 & 1.22 & 0.93 & 0.88 & 1.01 & 1.15 & 0.97 \\
\hline 500 & & 1.18 & $0.52^{b}$ & 0.99 & 0.74 & 0.78 & 2.13 & 1.06 & 0.82 & 0.89 & 1.02 & 0.86 & 1.00 & 1.53 & 1.13 & 1.06 \\
\hline Non-challenged & & 1.23 & $1.13^{\mathrm{a}}$ & 1.07 & 1.07 & $1.11^{\mathrm{a}}$ & $1.07^{b}$ & 1.16 & 1.04 & 1.07 & 0.94 & 1.09 & $1.15^{\mathrm{a}}$ & 1.22 & 1.07 & 1.23 \\
\hline Challenged & & 1.09 & $0.67^{\mathrm{b}}$ & 0.94 & 0.66 & $0.64^{b}$ & $3.51^{\mathrm{a}}$ & 0.93 & 0.88 & 0.83 & 1.30 & 0.70 & $0.73^{b}$ & 1.32 & 1.21 & 0.80 \\
\hline \multicolumn{17}{|l|}{$P$-value ${ }^{3}$} \\
\hline$B\llcorner J$ & & 0.780 & $<0.01$ & 0.788 & 0.018 & 0.219 & 0.500 & 0.843 & 0.085 & 0.663 & 0.360 & 0.323 & 0.324 & 0.078 & 0.957 & 0.561 \\
\hline Challenged & & 0.339 & 0.017 & 0.118 & $<0.01$ & $<0.01$ & $<0.01$ & $<0.01$ & 0.316 & 0.381 & 0.107 & $<0.01$ & $<0.01$ & 0.737 & 0.525 & 0.013 \\
\hline Challenged×BLJ & & 0.013 & 0.081 & 0.162 & $<0.01$ & 0.068 & 0.358 & $<0.01$ & 0.125 & 0.073 & 0.775 & $<0.01$ & 0.319 & 0.361 & 0.914 & 0.044 \\
\hline
\end{tabular}

a, b, c Means within the same column with different superscripts differ significantly $(P<0.05)$

${ }^{1} N E$ Co-challenged with Eimeria spp. and Clostridium perfringens; -, without NE challenge; +, with NE challenge

${ }^{2}$ SEM standard error of the mean

${ }^{3} P$-values represent the main effect of the diet, the main effect of NE challenged, and the interaction between the dietary treatments and NE challenged 


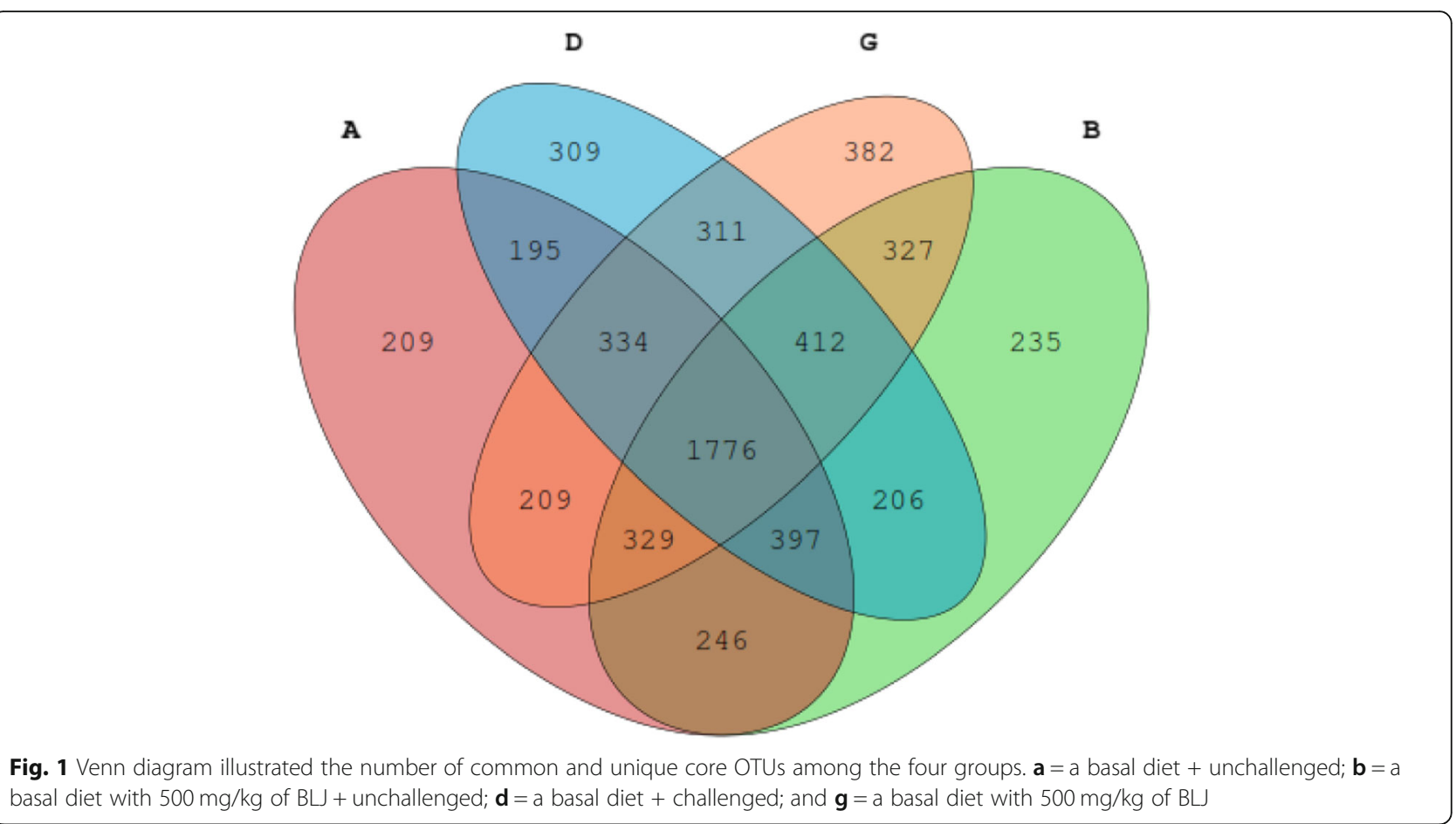

Table 9 Effect of BLJ on cecal microbiota a-diversity of the broiler chickens subjected to NE challenge

\begin{tabular}{|c|c|c|c|c|c|}
\hline Items & $\mathrm{NE}^{1}$ & Simpson & Chao 1 & ACE & Shannon \\
\hline \multicolumn{6}{|l|}{$\mathrm{B}\llcorner J, \mathrm{mg} / \mathrm{kg}$} \\
\hline 0 & - & 0.91 & 1747.37 & 1807.71 & 6.51 \\
\hline 0 & + & 0.93 & 1625.39 & 1656.49 & 6.92 \\
\hline 500 & - & 0.91 & 1725.20 & 1830.70 & 6.70 \\
\hline 500 & + & 0.95 & 1728.87 & 1856.10 & 7.19 \\
\hline $\mathrm{SEM}^{2}$ & & 0.01 & 49.89 & 55.50 & 0.14 \\
\hline \multicolumn{6}{|l|}{ Main effect } \\
\hline 0 & & 0.92 & 1686.38 & 1732.10 & 6.72 \\
\hline 500 & & 0.93 & 1727.03 & 1847.90 & 6.95 \\
\hline Non-challenged & & 0.91 & 1736.08 & 1819.20 & 6.61 \\
\hline Challenged & & 0.94 & 1677.13 & 1760.80 & 7.05 \\
\hline \multicolumn{6}{|l|}{$P$-value ${ }^{3}$} \\
\hline BLJ & & 0.723 & 0.702 & 0.320 & 0.402 \\
\hline Challenge & & 0.179 & 0.579 & 0.613 & 0.113 \\
\hline ChallengeXBLJ & & 0.679 & 0.556 & 0.423 & 0.878 \\
\hline
\end{tabular}

${ }^{1}$ NE Co-challenged with Eimeria spp. and Clostridium perfringens; -, without $\mathrm{NE}$ challenge; + , with NE challenge

${ }^{2}$ SEM standard error of the mean

${ }^{3} P$-values represent the main effect of the diet, the main effect of the NE challenge, and the interaction between the dietary treatments and NE challenge significant role in nutrient digestion and absorption [52]. In the current study, we further investigated the effect of adding BLJ on intestinal health of the NE-challenged broilers to explain the mechanisms by which BLJ improves FCR. NE infection alone led to higher gut lesions, atrophied villus height, longer crypt depths and a reduced VH/CD ratio; however, these changes were reversed, attenuated or alleviated by including BLJ in the diet, thus indicating that BLJ addition alleviated the mucosal atrophy and epithelial cell necrosis due to NE challenge. Consistent with our findings, broilers infected with $C$. perfringens and treated with combined sodium butyrate and EOs (ginger oil and carvacrol) protected with vegetable fat also yielded better BWG, increased villus lengths and $\mathrm{VH} / \mathrm{CD}$ ratios and decreased gross pathological and histopathological lesion scores compared with those of the controls [53]. Two previous studies demonstrated that feeding blends of sorbic acid, fumaric acid and thymol to broiler chickens reared under conventional conditions changed the intestinal morphology, resulting in longer villi and a greater $\mathrm{VH} /$ $\mathrm{CD}$ ratio [35, 47]. In addition, several studies have shown improved gut morphology and decreased gross intestinal lesion scores in NE-infected broiler chickens fed either EO-supplemented [18] or OA-treated diets [28]. Intestinal bacterial translocation to internal organs and serum FITC-D levels post-FITC-D gavage are also two important parameters commonly used to indirectly evaluate quality and extent of intestinal injury [54]. Our study further found that infected birds fed BLJ showed 


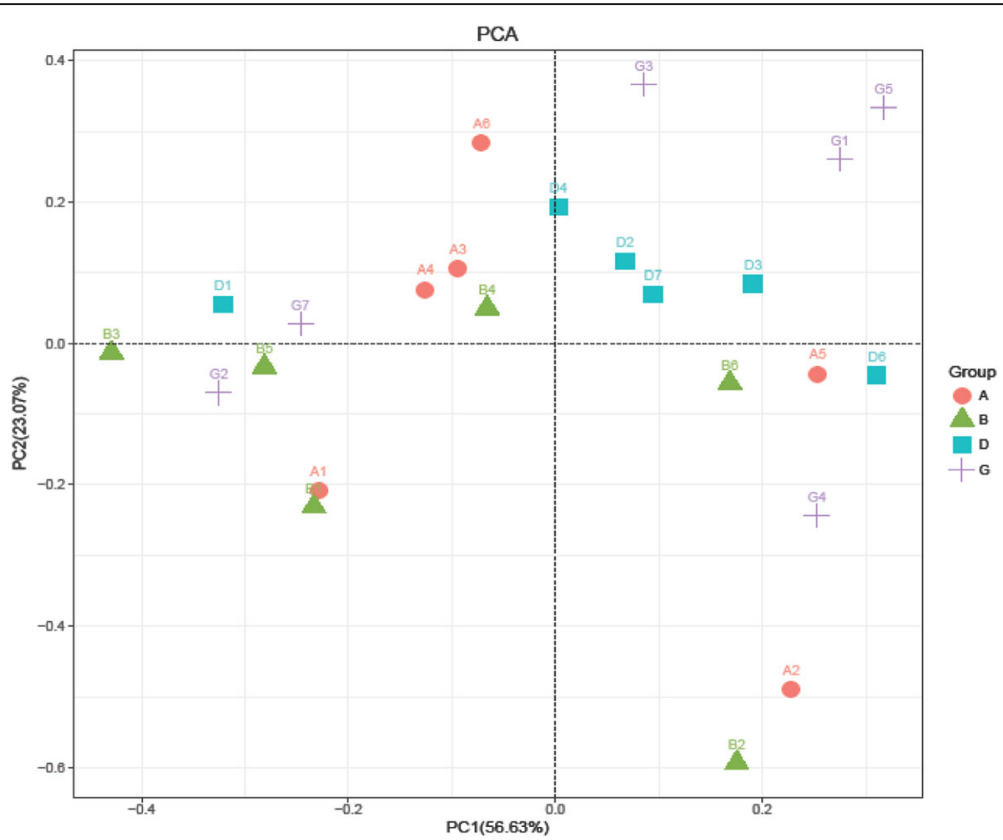

Fig. 2 Effect of BLJ on cecal microbiota beta-diversity of the broiler chickens subjected to SNE challenge. $\mathbf{a}=\mathrm{a}$ basal diet + unchallenged; $\mathbf{b}=\mathrm{a}$ basal diet with $500 \mathrm{mg} / \mathrm{kg}$ of BLJ + unchallenged; $\mathbf{d}=$ a basal diet + challenged; and $\mathbf{g}=$ a basal diet with $500 \mathrm{mg} / \mathrm{kg}$ of BLJ + challenged

lower C. perfringens loads in the liver and cecal contents and decreased serum FITC-D concentrations after oral administration of FITC-D in contrast to the NE-infected birds. These results indicated that including dietary BLJ inhibited C. perfringens growth, colonization and translocation and improved intestinal barrier integrity against NE-induced gut barrier injury in broiler chickens under $\mathrm{NE}$ infection. Likewise, previous studies also reported that the EOA combination can decrease C. perfringens colonization and proliferation in chicken guts [54]. Improved gut morphology, reduced gut lesion scores and decreased intestinal epithelial permeability in NEinfected birds that received BLJ were possibly attributed to the antibacterial traits of the EOAs [34], EOs [11] or OAs [25]. The beneficial effect on FCR in the BLJ-fed birds with or without NE infection may have been

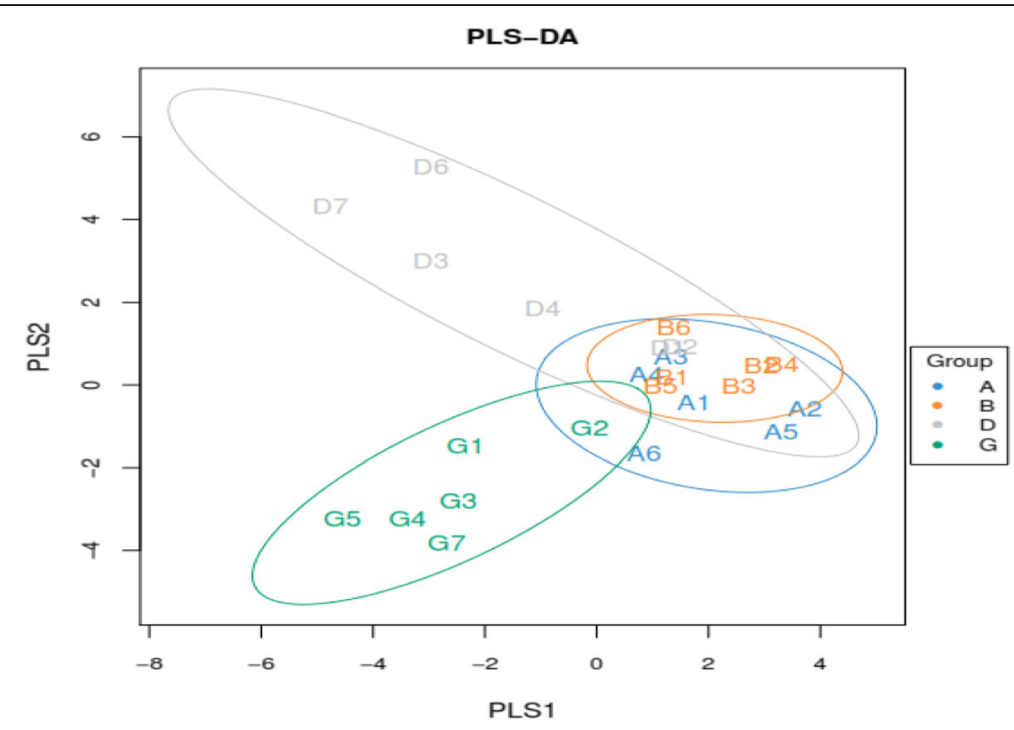

Fig. 3 Partial least squares discriminant analysis (PLS-DA) scores derived from cecal microbiota of broiler chickens infected with NE (indicating the degree of reliability of PCA analysis). (Difference of cecal microbiota relative abundance at a general level). $\mathbf{a}=\mathrm{a}$ basal diet + unchallenged; $\mathbf{b}=\mathrm{a}$ basal diet with $500 \mathrm{mg} / \mathrm{kg}$ of BLJ + unchallenged; $\mathbf{d}=$ a basal diet + challenged; and $\mathbf{g}=$ a basal diet with $500 \mathrm{mg} / \mathrm{kg}$ of BLJ + challenged 


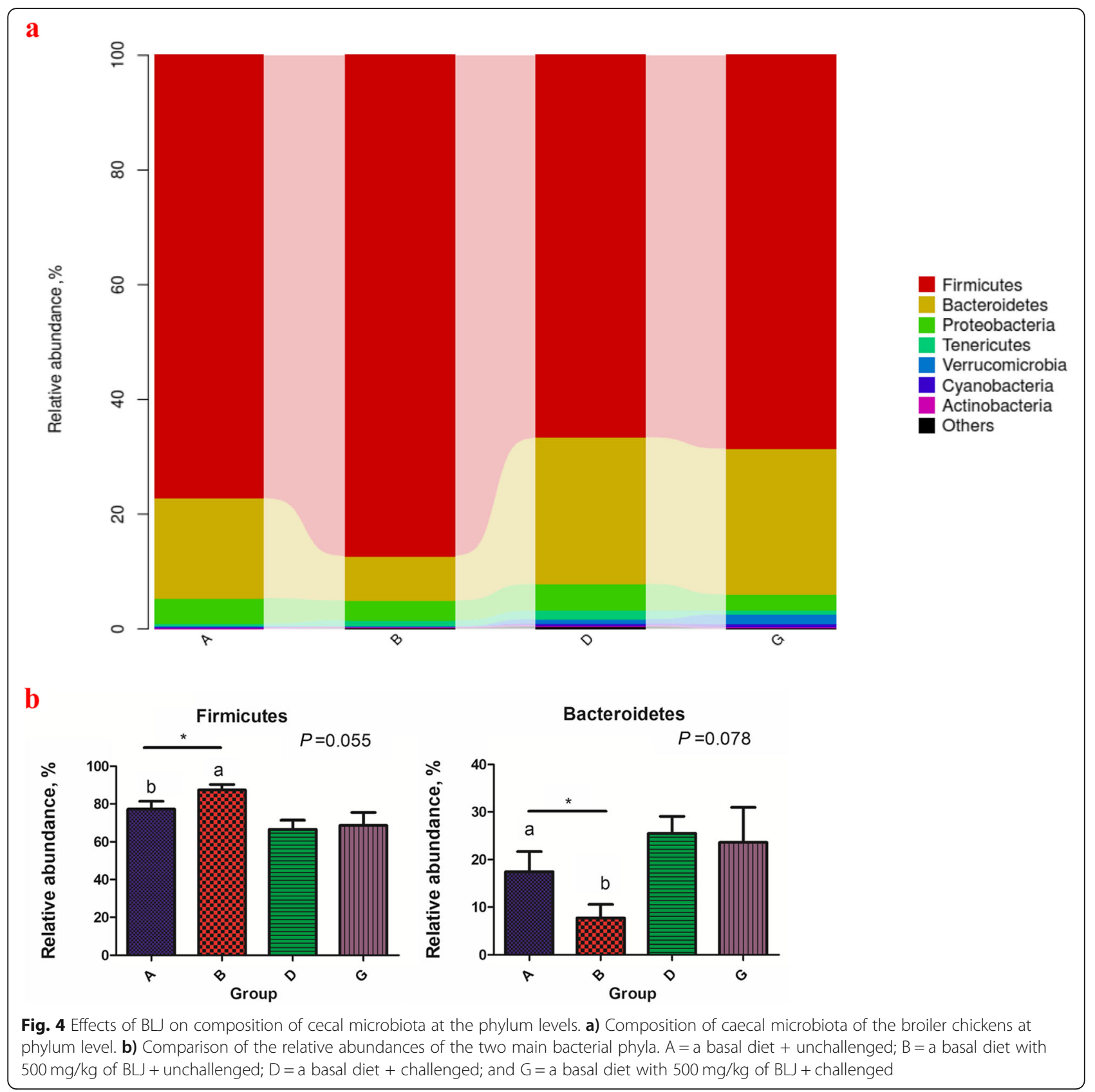

attributed to gut health improved by BLJ administration. Therefore, our results suggested that BLJ appeared to be effective in lessening the NE lesion severity.

The intestinal barrier is regulated by tight junction proteins (TJPs) that consist of several unique proteins, including the junction adhesion molecule, the transmembrane protein, occludin, members of the claudin family and linker proteins such as the zonula occludin protein family $(\mathrm{ZO})$. This mechanical barrier plays an important role in the absorption of nutrients, electrolytes and water, as well as maintaining intestinal-barrier integrity and function and protecting the gut from enteric pathogen invasion. Intestinal TJP barrier disruption leads to endogenous infection and sustained inflammation and tissue damage, and it reduces nutrient absorption [55]. In this study, NE infection remarkably downregulated occludin and ZO-1 mRNA levels, while the NE-infected birds fed BLJ showed upregulated claudin-1 mRNA expression levels in the jejunum compared with those of untreated NEinfected birds. These results were consistent with previous findings in broilers fed EOAs [15]. Additionally, increased TJP gene expression and improved intestinal barrier function were observed in EO (thymol and carvacrol)-treated broilers challenged with $C$. perfringens [56]. Furthermore, birds that 


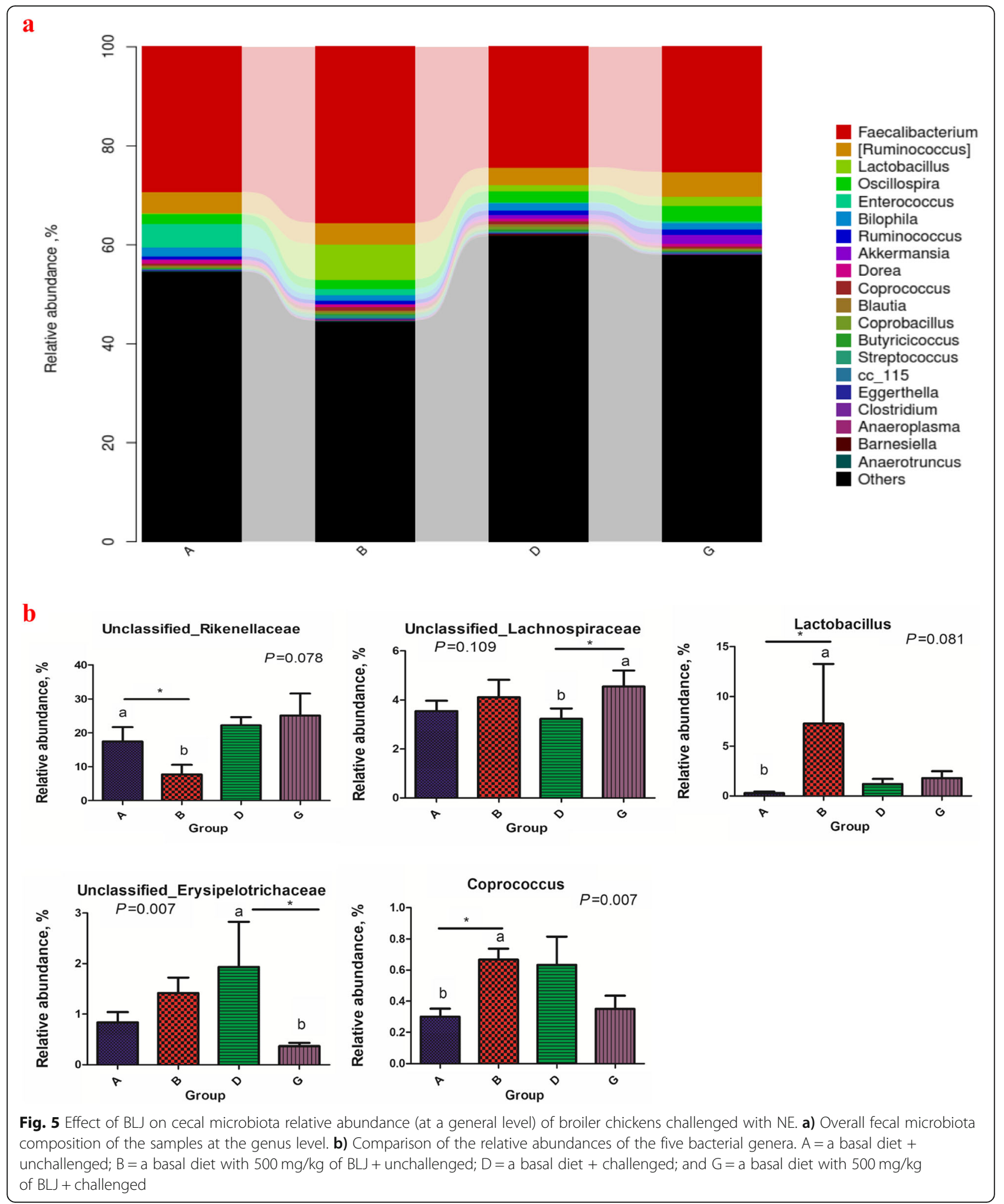

received BLJ showed upregulated mucin-2 mRNA levels compared with those of the unsupplemented groups, regardless of NE infection. Claudin- 1 is a member of the multiplespanning, transmembrane, claudin protein family, which plays important roles in barrier formation and paracellular selectivity in various tissues [57]. Mucin-2, secreted by goblet cells, covers the intestinal epithelial surface and plays a major role in protecting the intestinal epithelium from infection 
and maintaining intestinal mucosal barrier integrity, immune hemostasis and gut health [58]. Here, increased claudin-1 gene expression was observed in the jejunums of NE birds administered BLJ, indicating that BLJ addition helps protect the gut barrier from direct contact with pathogenic bacteria in NE-infected broilers. Enhanced TJPs following BLJ supplementation resulted in reduced gut permeability and pathogen invasion. Thus, our results also suggested that BLJ, a protective EOA blend, may help maintain gut health. Interestingly, we also found that dietary BLJ supplementation significantly downregulated ZO-1 expression levels in the jejunum compared with those of the unsupplemented controls regardless of NE challenge. In contrast with previous results, broiler chickens fed carvacrol EOs or coated butyrate exhibited upregulated ZO-1 and ZO-2 mRNA levels in the intestinal mucosa [15]. The $\mathrm{ZO}$ proteins, $\mathrm{ZO}-1, \mathrm{ZO}-2$ and $\mathrm{ZO}-3$, are important molecules that interact directly with occludin, claudins and actin thereby providing a scaffold that facilitates regulation of the expression and distribution of the TJP complex [59]. The changes suggested that BLJ supplementation differentially regulated TJP complex expression and distribution in the gut but did not damage or alter its intact structure. The reason that BLJ downregulates ZO-1 requires further investigation.

TLR-mediated signaling pathways are involved in regulating intestinal epithelial barrier integrity [60]. In our study, NE infection significantly increased $I F N-\gamma$ and $I G F-2$ mRNA levels and downregulated TLR-4, adaptor protein tumor necrosis factor receptor (TNFR)-associated factor 6 (TRAF-6), NF- $\mathrm{B}$, TNFSF15, TLR-activating negative regulators TOLLIP, PISK and SOCS-6 and EGFR mRNA expression in the jejunum compared with the unchallenged control. Suppression of negative regulators of the TLR signaling pathway suggested that the TLR signaling pathway was activated, resulting in inflammatory cytokine production. Upregulated IFN- $\gamma$ gene mRNA levels were observed in the untreated NEinfected birds, which were consistent with previous studies [61]. These results showed that NE infection differentially modulated intestinal immune-related gene and growth factor gene expression, thus activating intestinal immuno-inflammatory responses. NE infection markedly increased intestinal inflammation, possibly by increasing proinflammatory cytokine IFN- $\gamma$ gene expression, whilst downregulating TLR-activating negative regulators in broilers. However, dietary BLJ supplementation remarkably downregulated TLR-4 and TRAF- 6 gene expression levels, decreased $I L-1 \beta$ gene expression levels and increased $A 20$ and SOCS-6 mRNA levels in the jejunal mucosa of broilers regardless of NE infection. This result suggested that BLJ showed anti-inflammatory functions in the chicken intestines by upregulating negative-factor SOCS-6 and A20 gene expression and inhibiting TLR4mediated signal pathway activation. Additionally, NE- infected birds fed diets containing BLJ displayed decreased relative gene expression of TRAF-6, TNFSF15 and TOLLIP and reduced TLR2 gene expression levels but displayed increased IGF-2 mRNA levels in the jejunum compared with those in the untreated NE-infected birds. Proinflammatory cytokines, such as TNF- $\alpha$, IFN- $\gamma$ and IL- $1 \beta$, are reported to increase intestinal permeability and tissue damage by dysregulating TJPs [62], while various regulatory peptides including anti-inflammatory cytokines (TGF- $\beta$, IL-4 and IL-10), growth factors (EGF, GLP-2 and IGF-2) and negative regulators (A20, SOCS, TOLLIP and PI3K) of the TLR signaling pathway protect intestinal barrier function by regulating TJP expression and facilitating repair of damaged gut tissue [63]. Here, NE infection compromised the intestinal epithelial barrier integrity, possibly associated with intestinal immuno-inflammatory responses, while suppressing TLR-2, TRAF-6 and proinflammatory cytokine TNFSF15 mRNA and upregulating growth factor $I G F-2$ mRNA via BLJ in the intestines of the BLJ-fed chickens following NE infection. This result indicated that BLJ pretreatment could reduce the progress and development of intestinal inflammation, alleviate NEinduced intestinal inflammation, improve gut health and protect the intestinal barrier structure as evidenced by the attenuated gut lesions, reduced bacterial translocation to the liver and increased VH/CD ratios in the jejunum. The anti-inflammatory effect of BLJ has generally been attributed to the antimicrobial and immune-regulating actions of the EOs [17] or OAs [64] in the BLJ. The reduced intestinal inflammation may eventually lead to improved gut health and FCR in BLJ-treated chickens, possibly by modifying the TLR-mediated signaling pathway.

The gut microbiota constitutes a highly complex ecosystem that interacts with the host and profoundly affects the physiological, immunological, nutritional and metabolic status of the host $[65,66]$. To further investigate the mechanism underlying BLJ mitigating NE-induced gut injury, the cecal microbiota structure was analyzed via Illumina MiSeq sequencing. This study revealed no differences in $\alpha$-diversity of the cecal microbiota between the four experimental groups, which was consistent with previous results [67]. In addition, principal component analysis showed that BLJ supplementation, NE challenge or both altered the $\beta$-diversity of the cecal microbiota, indicating that these treatments significantly affected the intestinal bacterial community profiles. However, NE challenge reduced the relative abundance of the phylum Firmicutes (67.65\% vs. $82.27 \%$ ) and increased the relative levels of Bacteroidetes compared with those of the unchallenged group, which helps explain the impaired BWG in the NE-infected birds, consistent with previous research [67]. We also found that the relative abundance of Firmicutes increased, while the relative abundance of Bacteroidetes decreased after BLJ treatment in unchallenged birds. Increases in fecal Firmicutes have been associated with increased 
nutrient absorption [68] and body weight gain [69], whereas increases in fecal Bacteroidetes have been associated with decreased nutrient absorption [67, 70]. Therefore, a higher abundance of Firmicutes might enhance energy absorption in birds fed BLJ, resulting in the improved FCR observed in our study.

Infected birds administered BLJ showed an increased percentage of Unclassified_Lachnospiraceae and a significantly decreased relative abundance of Erysipelotrichaceae. Additionally, compared with the untreated uninfected birds, the uninfected birds fed BLJ displayed increased relative abundances of Lactobacillus and Coprococcus and fewer Rikenellaceae. Similarly, previous studies have shown that EOA blends increased Lactobacillus spp. counts in the ileal digesta in pigs [71] and chickens [48]. A supplemental EO blend (thymol and carvacrol) increased ileal Lactobacillus populations and reduced the effect of NE due to $C$. perfringens in chickens [49]. OAs added to broiler feed can increase Lactobacillus populations and reduce pathogenic bacteria in the gastrointestinal tract [72]. Therefore, our findings suggested that BLJ supplementation altered the cecal microbial communities in broiler chickens, regardless of NE infection. Lactobacillus spp. could inhibit intestinal inflammatory responses and displace pathogenic bacteria including Salmonella and $C$. perfringens from the gut by producing OAs or bacteriocins [73]. Members of the Lachnospiraceae family, including Coprococcus, Roseburia spp. and Eubacterium rectale, were found to have a protective effect in patients with colon cancer by producing n-butyrate [68], they suppressed C. difficile in the mouse gut [69] and positively correlated with feed conversion efficiency in broiler chickens [70]. Erysipelotrichaceae abundance has been negatively correlated with body fat weight, the colonic butyrate concentration and intestinal health [74]. Rikenellaceae abundance has been positively correlated with clinical disease severity [75], and a reduced proportion of Rikenellaceae is considered to be a signature of a healthy gut. Recent evidence suggested that butyrate reduces the incidence and severity of NE, thus preventing ascending infections when added to feed [76]. Therefore, higher abundances of Lactobacillus, butyrate-producing Unclassified_Lachnospiraceae and Coprococcus, and a relatively lower proportion of Erysipelotrichaceae and Rikenellaceae, are present in the intestines of BLJ-treated broiler chickens regardless of NE infection, suggesting that including BLJ into the diets of birds can improve gut health by promoting the growth of potentially beneficial intestinal microorganisms and inhibiting the proliferation of harmful bacteria. Therefore, our study suggested that dietary BLJ benefitted gut health, and the mechanism for this effect may involve altering the gut microbial communities. Further fecal-metabolome analyses are required to explore the impact of BLJ on fecal metabolite profiles. These analyses may enable possible causal links to be established between BLJ, probiotics, metabolites and gut function.

\section{Conclusions}

In summary, the protected EOs and organic acid blends (BLJ) effectively ameliorated NE-induced intestinal injury, possibly by regulating the intestinal microbial communities and differentially modulating the intestinal mucosal immune responses and barrier function. These findings indicate that BLJ may be a potential and promising candidate for preventing NE in broiler chickens.

\section{Abbreviations \\ A20: Protein A20; AFI: Average feed intake; BWG: Body weight gain; CD: Crypt depth; CFU: Colony-forming unit; EGFR: Epidermal growth factor receptor; FCR: Feed conversion ratio; GLP-2: Glucagon-like peptide-2; IFN-Y: Interferon- Y; IGF-2: Insulin-like growth factor-2; IL: Interleukin; MyD88: Myeloid differential protein-88; NE: Necrotic enteritis; NF-KB: Nuclear factor kappa- light-chain-enhancer of activated B cells; NRC: National Research Council; PI3K: Phosphatidylinositol 3-kinase; SOCS: Suppressor of cytokine signaling; TGF- $\beta 3$ : Transforming growth factor beta 3; TLR: Toll-like receptor; TNFSF15: Tumor necrosis factor superfamily 15; TOLLIP: Toll-interacting protein; TRAF-6: TNF receptor-associated factor 6; VH: Villous height; VH:CD ratio: The ratio of villus height to crypt depth; ZO-1: Zonula occludens-1}

\begin{abstract}
Acknowledgements
The authors are grateful to the staff of the Department of Animal Science and Technology of the China Agricultural University for their valuable assistance in conducting the experiments. We acknowledge Menon Animal Nutrition Technology Co. Ltd., Shanghai, China, for providing the protected essential oil and organic acid products. We thank Traci Raley, MS, ELS, from Liwen Bianji, Edanz Editing China (mww.liwenbianji.cn/ac) for editing a draft of this manuscript.
\end{abstract}

\section{Authors' contributions}

ZW and VHP designed the research; VHP, LK, YG, JH, WZ and WA performed the research and analyzed the data; VHP wrote the manuscript; ZW, TR and YG participated in the revision of the manuscript. All authors contributed to data interpretation and approved the final version of the manuscript.

\section{Funding}

This research was funded by the National Key Research and Development Plan (No. 2107YFD0500506) and the National Special Fund for Agro-scientific Research in the Public Interest (20140304-07). The funders had no role in the study design, analysis or writing of this article.

\section{Availability of data and materials}

All data generated or analyzed during this study are available from the corresponding author by request. The datasets supporting the conclusions of this article are included in the article.

\section{Ethics approval and consent to participate}

All study procedures were approved by the Animal Care and Use Committee of China Agricultural University (permit number: SYXK 2019-0026) and were in accordance with the Beijing Guidelines for Experimental Animals established by the Ministry of Science and Technology (Beijing, China). All efforts were made to minimize the suffering of the animals.

\section{Consent for publication}

Not applicable.

\section{Competing interests}

The authors declare that no competing interests exist. The manuscript has not been published previously.

\section{Author details}

${ }^{1}$ State Key Laboratory of Animal Nutrition, College of Animal Science and Technology, China Agricultural University, Beijing 100193, China. ${ }^{2}$ Faculty of Animal Science and Veterinary Medicine, Thai Nguyen University Agriculture and Forestry, Thai Nguyen, Vietnam. ${ }^{3}$ Menon Animal Nutrition Technology Co. Ltd., Shanghai, China. 


\section{Received: 10 September 2019 Accepted: 22 December 2019} Published online: 21 February 2020

\section{References}

1. Timbermont $L$, Haesebrouck F, Ducatelle R, Van Immerseel F, Timbermont $L$, Haesebrouck F, et al. Necrotic enteritis in broilers : an updated review on the pathogenesis. Avian Pathol. 2011;40:341-7. https://doi.org/10.1080/ 03079457.2011.590967.

2. Immerseel F Van, Rood Jl, Moore RJ, Titball RW. Rethinking our understanding of the pathogenesis of necrotic enteritis in chickens 2008; 32-36. doi:https://doi.org/10.1016/j.tim.2008.09.005.

3. Brenes A, Roura E. Essential oils in poultry nutrition: Main effects and modes of action. Anim Feed Sci Technol. 2010;158:1-14. https://doi.org/10.1016/j. anifeedsci.2010.03.007

4. Henri I, Bassolé N, HRJ. Essential oils in combination and their antimicrobial properties. Molecules. 2012;17:3989-4006. https://doi.org/10.3390/ molecules17043989.

5. Gopi M, Karthik K, Manjunathachar HV, Kesavan M, Dashprakash M, Balaraju $\mathrm{BL}$, et al. Review article essential oils as a feed additive in poultry nutrition. Adv Anim Vet Sci. 2014;2:1-7.

6. Devi KP, Nisha SA, Sakthivel R, Pandian SK. Eugenol ( an essential oil of clove ) acts as an antibacterial agent against Salmonella Typhi by disrupting the cellular membrane. J Ethnopharmacol. 2010;130:107-15. https://doi.org/ 10.1016/j.jep.2010.04.025

7. Stevanovic ZD, Bošnjak-Neumüller J, Ivana Pajic-Lijakovic JR, MV. Essential oils as feed additives — Future perspectives. Molecules. 2018;23. https://doi. org/10.3390/molecules23071717.

8. Swamy MK, Akhtar MS, Sinniah UR. Antimicrobial properties of plant essential oils against human pathogens and their mode of action: an updated review. Evidence-Based Complement Altern Med. 2016;2016. https://doi.org/10.1155/2016/3012462

9. Du E, Gan L, Li Z, Wang W, Liu D, Guo Y. In vitro antibacterial activity of thymol and carvacrol and their effects on broiler chickens challenged with Clostridium perfringens. J Anim Sci Biotechnol. 2015;6:1-12. https://doi.org/ 10.1186/s40104-015-0055-7.

10. Jang IS, Ko YH, Kang SY, Lee CY. Effect of a commercial essential oil on growth performance, digestive enzyme activity and intestinal microflora population in broiler chickens. Anim Feed Sci Technol. 2007;134:304-15. https://doi.org/10.1016/j.anifeedsci.2006.06.009.

11. Chowdhury S, Mandal GP, Patra AK, Kumar P, Samanta I, Pradhan S, et al. Different essential oils in diets of broiler chickens: 2. Gut microbes and morphology, immune response, and some blood profile and antioxidant enzymes. Anim Feed Sci Technol. 2018;236:39-47. https://doi.org/10.1016/j. anifeedsci.2017.12.003

12. Chowdhury S, Mandal GP, Patra AK. Different essential oils in diets of chickens: 1. Growth performance, nutrient utilisation, nitrogen excretion, carcass traits and chemical composition of meat. Anim Feed Sci Technol. 2018;236:86-97. https://doi.org/10.1016/j.anifeedsci.2017.12.002.

13. Pirgozliev V, Bravo D, Mirza MW, Rose SP. Growth performance and endogenous losses of broilers fed wheat-based diets with and without essential oils and xylanase supplementation. Poult Sci. 2015;94:1227-32. https://doi.org/10.3382/ps/peu017.

14. Mitsch P, Ko B, Gabler C, Losa R, Zimpernik I. The effect of two different blends of essential oil components on the proliferation of Clostridium perfringens in the intestines of broiler chickens. Poult Sci. 2004;83:669-75.

15. Liu S, Song M, Yun W, Lee J, Lee C, Kwak W, et al. Effects of oral administration of different dosages of carvacrol essential oils on intestinal barrier function in broilers. J Anim Physiol Anim Nutr. 2018;102:1257-65. https://doi.org/10.1111/jpn.12944

16. Peng QY, Li JD, Li Z, Duan ZY, Wu YP. Effects of dietary supplementation with oregano essential oil on growth performance, carcass traits and jejunal morphology in broiler chickens. Anim Feed Sci Technol. 2016;214: 148-53. https://doi.org/10.1016/j.anifeedsci.2016.02.010.

17. Zeng Z, Zhang S, Wang H, Piao X. Essential oil and aromatic plants as feed additives in non-ruminant nutrition: a review. J Anim Sci Biotechnol. 2015;6. https://doi.org/10.1186/s40104-015-0004-5.

18. Sun Q, Liu D, Guo S, Chen Y, Guo Y. Effects of dietary essential oil and enzyme supplementation on growth performance and gut health of broilers challenged by Clostridium perfringens. Anim Feed Sci Technol. 2015; 207:234-44. https://doi.org/10.1016/j.anifeedsci.2015.06.021.
19. Hashemipour H, Khaksar V, Rubio LA, Veldkamp T, Van Krimpen MM. Effect of feed supplementation with a thymol plus carvacrol mixture, in combination or not with an NSP-degrading enzyme, on productive and physiological parameters of broilers fed on wheat-based diets. Anim Feed Sci Technol. 2016;211:117-31.

20. Bravo D, Pirgozliev $V$, Rose SP. A mixture of carvacrol, cinnamaldehyde, and capsicum oleoresin improves energy utilization and growth performance of broiler chickens fed maize-based diet. J Anim Sci. 2014;92:1531-6. https:// doi.org/10.2527/jas.2013-6244.

21. Emami NK, Samie A, Rahmani HR, Ruiz-feria CA. The effect of peppermint essential oil and fructooligosaccharides, as alternatives to virginiamycin, on growth performance, digestibility, gut morphology and immune response of male broilers. Anim Feed Sci Technol. 2012;175:57-64. https://doi.org/10. 1016/j.anifeedsci.2012.04.001.

22. Kazempour $F$, Jahanian R. Effects of different organic acids on performance, ileal microflora, and phosphorus utilization in laying hens fed diet deficient in non-phytate phosphorus. Anim Feed Sci Technol. 2017;223:110-8. https:// doi.org/10.1016/j.anifeedsci.2016.11.006.

23. Li Y, Fu X, Ma X, Geng S, Jiang X, Huang Q. Intestinal microbiomeMetabolome responses to essential oils in piglets. Front Microbiol. 2018;9:113. https://doi.org/10.3389/fmicb.2018.01988.

24. Diaz Carrasco JM, Redondo LM, Redondo EA, Dominguez JE, Chacana AP, Fernandez Miyakawa ME. Use of plant extracts as an effective manner to control Clostridium perfringens induced necrotic enteritis in poultry. Biomed Res Int. 2016;2016. https://doi.org/10.1155/2016/3278359.

25. Paul SK, Halder G, Mondal MK, Samanta G. Effect of organic acid salt on the performance and gut health of broiler chicken. J Poult Sci. 2007:44:389-95.

26. Santos FSDL, Donoghue AM, Venkitanarayanan K, Metcalf JH, Dirain ML, Aguiar VF, et al. Therapeutic supplementation of caprylic acid in feed reduces Campylobacter jejuni colonization in broiler chicks. Appl Environ Microbiol. 2008;74:4564-6. https://doi.org/10.1128/AEM.02528-07.

27. Skrivanova E, GD MM, JK. Susceptibility of Clostridium perfringens to C2 C18 fatty acids. Lett Appl Microbiol. 2005;41:77-81. https://doi.org/10.1111/j. 1472-765X.2005.01709.X.

28. Song B, Li H, Wu Y, Zhen W, Wang Z, Xia Z, et al. Effect of microencapsulated sodium butyrate dietary supplementation on growth performance and intestinal barrier function of broiler chickens infected with necrotic enteritis. Anim Feed Sci Technol. 2017;232:6-15. https://doi.org/10. 1016/j.anifeedsci.2017.07.009.

29. Geier MS, Mikkelsen LL, Torok VA, Allison GE, Olnood CG, Boulianne M, et al. Comparison of alternatives to in-feed antimicrobials for the prevention of clinical necrotic enteritis. J Appl Microbiol. 2010;109:1329-38. https://doi. org/10.1111/j.1365-2672.2010.04758.X.

30. Diao H, Gao Z, Yu B, Zheng P, He J, Yu J, et al. Effects of benzoic acid ( VevoVitall ${ }^{\oplus}$ ) on the performance and jejunal digestive physiology in young pigs. J Anim Sci Biotechnol. 2016;7:1-7. https://doi.org/10.1186/s40104-0160091-y.

31. Kluge H, Broz J, Eder K. Effect of benzoic acid on growth performance, nutrient digestibility, nitrogen balance, gastrointestinal microflora and parameters of microbial metabolism in piglets. J Anim Physiol Anim Nutr (Berl). 2006:90:316-24. https://doi.org/10.1111/j.1439-0396.2005.00604.x.

32. Zentek J, Ferrara F, Vahjen W, Van Kessel AG. Nutritional and physiological role of medium-chain triglycerides and medium-chain fatty acids in piglets. Anim Health Res Rev. 2011;12:83-93. https://doi.org/10.1017/ S1466252311000089.

33. Omonijo FA, Ni L, Gong J, Wang Q, Lahaye L, Yang C. Essential oils as alternatives to antibiotics in swine production. Anim Nutr. 2018;4:126-36. https://doi.org/10.1016/j.aninu.2017.09.001.

34. Cerisuelo A, Marín C, Sánchez-Vizcaíno F, Gómez EA, De La Fuente JM, Durán $\mathrm{R}$, et al. The impact of a specific blend of essential oil components and sodium butyrate in feed on growth performance and Salmonella counts in experimentally challenged broilers. Am Hist Rev. 2014;119:599606. https://doi.org/10.1093/ahr/119.2.599.

35. Yang $X$, Xin H, Yang C, Yang X. Impact of essential oils and organic acids on the growth performance, digestive functions and immunity of broiler chickens. Anim Nutr. 2018:4:388-93. https://doi.org/10.1016/j.aninu.2018.04.005.

36. Isabel B, Santos Y. Effects of dietary organic acids and essential oils on growth performance and carcass characteristics of broiler chickens. J Appl Poult Res. 2009;18:472-6. https://doi.org/10.3382/japr.2008-00096.

37. Wu Y, Shao Y, Song B, Zhen W, Wang Z, Guo Y, et al. Effects of Bacillus coagulans supplementation on the growth performance and gut health of 
broiler chickens with Clostridium perfringens-induced necrotic enteritis. J Anim Sci Biotechnol. 2018;9:1-14. https://doi.org/10.1186/s40104-017-0220-2

38. Shao Y, Guo Y, Wang Z. $\beta-1,3 / 1,6$-Glucan alleviated intestinal mucosal barrier impairment of broiler chickens challenged with Salmonella enterica serovar Typhimurium. Poult Sci. 2013;92:1764-73.

39. Baxter MFA, Merino-Guzman R, Latorre JD, Mahaffey BD, Yang Y, Teague KD, et al. Optimizing fluorescein isothiocyanate dextran measurement as a biomarker in a 24-h feed restriction model to induce gut permeability in broiler chickens. Front Vet Sci. 2017;4:1-6. https://doi.org/10.3389/fvets.2017.00056.

40. Livak KJ, Schmittgen TD. Analysis of relative gene expression data using real- time quantitative PCR and the $2^{-\Delta \Delta C}$ T method. Methods. 2001;25:4028. https://doi.org/10.1006/meth.2001.1262.

41. Magoc T, Salzberg SL. FLASH : fast length adjustment of short reads to improve genome assemblies. Bioinformatics. 2011;27:2957-63. https://doi. org/10.1093/bioinformatics/btr507.

42. Caporaso JG, Kuczynski J, Stombaugh J, Bittinger K, Bushman FD, Costello EK, et al. QIIME allows analysis of high-throughput community sequencing data. Nat Methods. 2011;7:335-6. https://doi.org/10.1038/nmeth.f.303.QIIME.

43. Lozupone CA, Hamady M, Kelley ST, Knight R. Quantitative and qualitative $\beta$ diversity measures lead to different insights into factors that structure microbial communities. Appl Environ Microbiol. 2007;73:1576-85. https://doi. org/10.1128/AEM.01996-06.

44. Ramette A. Multivariate analyses in microbial ecology. FEMS Microbiol Ecol. 2007;62:142-60. https://doi.org/10.1111/j.1574-6941.2007.00375.x.

45. Zaura E, Keijser BJF, Huse SM, Crielaard W. Defining the healthy "core microbiome" of oral microbial communities. BMC Microbiol. 2009;9:1-12 https://doi.org/10.1186/1471-2180-9-259.

46. Chen Y, Yang F, Lu H, Wang B, Chen Y, Lei D, et al. Characterization of fecal microbial communities in patients with liver cirrhosis. Hepatology. 2011;54: 562-72. https://doi.org/10.1002/hep.24423.

47. Liu $Y$, Yang $X$, Xin H, Chen S, Yang C, Duan Y, et al. Effects of a protected inclusion of organic acids and essential oils as antibiotic growth promoter alternative on growth performance, intestinal morphology and gut microflora in broilers. Anim Sci J. 2017:88:1414-24. https:/doi.org/10.1111/asj.12782.

48. Yang X, Liu Y, Yan F, Yang C, Yang X. Effects of encapsulated organic acids and essential oils on intestinal barrier, microbial count, and bacterial metabolites in broiler chickens. Poult Sci. 2019;0:1-8. https://doi.org/10.3382/ps/pez031.

49. Giannenas I, Papaneophytou CP, Tsalie E, Pappas I, Triantafillou E, Tontis D, et al. Dietary supplementation of benzoic acid and essential oil compounds affects buffering capacity of the feeds, performance of Turkey poults and their antioxidant status, $\mathrm{pH}$ in the digestive tract, intestinal microbiota and morphology. Asian Australas J Anim Sci. 2014;27:225-36.

50. Fascina VB, Sartori JR, Gonzales E, De FB, Mailinch I, Pereira G, et al. Phytogenic additives and organic acids in broiler chicken diets. Rev Bras Zootec. 2012;41:2189-97. https://doi.org/10.1590/S151635982012001000008

51. Zhai H, Liu H, Wang S, Wu J, Kluenter AM. Potential of essential oils for poultry and pigs. Anim Nutr. 2018;4:179-86. https://doi.org/10.1016/j.aninu.2018.01.005.

52. Celi P, Cowieson AJ, Fru-nji F, Steinert RE, Kluenter A, Verlhac V. Gastrointestinal functionality in animal nutrition and health : new opportunities for sustainable animal production. Anim Feed Sci Technol. 2017;234:88-100. https://doi.org/10.1016/j.anifeedsci.2017.09.012.

53. Jerzsele A, Szeker K, Csizinszky R, Gere E, Jakab C, Mallo JJ, et al. Efficacy of protected sodium butyrate, a protected blend of essential oils, their combination, and Bacillus amyloliquefaciens spore suspension against artificially induced necrotic enteritis in broilers. Poult Sci. 2012;91:837-43. https://doi.org/10.3382/ps.2011-01853.

54. Celikbilek A, Deniz G, Orman A, Gencoglu H, Kara C. Effects of a combination of dietary organic acid blend and oregano essential oil (Lunacompacid ${ }^{\circledR}$ Herbex dry) on the performance and Clostridium perfringens proliferation in the ileum of broiler chickens. J BiolEnviron Sci. 2014:8:61-9. https://doi.org/10.1155/2014/423751.

55. Peterson LW, Artis D. Intestinal epithelial cells: regulators of barrier function and immune homeostasis. Nat Rev Immunol. 2014;14:141-53. https:/doi.org/10.1038/nri3608.

56. Du E, Wang W, Gan L, Li Z, Guo S, Guo Y. Effects of thymol and carvacrol supplementation on intestinal integrity and immune responses of broiler chickens challenged with Clostridium perfringens. J Anim Sci Biotechnol. 2016;7:1-10. https://doi.org/10.1186/s40104-016-0079-7.

57. Suzuki T. Regulation of intestinal epithelial permeability by tight junctions. Cell Mol Life Sci. 2013;70:631-59. https://doi.org/10.1007/ s00018-012-1070-x.
58. Kim YS, Ho SB. Intestinal goblet cells and mucins in health and disease recent insights and progress. Curr Gastroenterol Rep. 2010;12:319-30. https://doi.org/10.1007/s11894-010-0131-2.

59. Bauer H, Steinbacher $P$, Lametschwandtner A, Bauer HC. The dual role of zonula occludens (ZO) proteins. J ofBiomedicine Biotechnol. 2010;2010:11. https://doi.org/10.1155/2010/402593.

60. Nighot M, Al-sadi R, Guo S, Rawat M, Nighot P, Watterson MD. Lipopolysaccharide-induced increase in intestinal epithelial tight permeability is mediated by Toll-like receptor 4 / myeloid differentiation primary response 88 ( MyD88) activation of myosin light chain kinase expression. Am J Pathol. 2017;187:2698-710. https://doi.org/10.1016/j.ajpath. 2017.08.005

61. Broom LJ, Kogut $\mathrm{MH}$. Deciphering desirable immune responses from disease models with resistant and susceptible chickens. Poult Sci. 2019;98: 1634-42. https://doi.org/10.3382/ps/pey535.

62. Edelblum $\mathrm{KL}$, Turner JR. The tight junction in inflammatory disease: communication breakdown. Curr Opin Pharmacol. 2009;9:715-20. https:// doi.org/10.1016/j.coph.2009.06.022.The.

63. Jeong $E$, Lee JY. Intrinsic and extrinsic regulation of innate immune receptors. Yonsei Med J. 2011;52:379-92. https://doi.org/10.3349/ymj.2011.52.3.379.

64. Segain J, De Blétière DR, Bourreille A, Leray V, Gervois N, Rosales C, et al. Butyrate inhibits inflammatory responses through NF-kB inhibition: implications for Crohn's disease. Gut. 2000;47:397-403.

65. Sommer F, Bäckhed F. The gut microbiota - masters of host development and physiology. Nat Rev Microbiol. 2013. https://doi.org/10.1038/nrmicro2974.

66. Hiippala K, Jouhten H, Ronkainen A, Hartikainen A. Veera Kainulainen JJ and RS. The potential of gut commensals in reinforcing intestinal barrier function and alleviating inflammation. Nutr Rev. 2018;10. https://doi.org/10.3390/nu10080988.

67. Bortoluzzi C, Pedroso AA, Mallo JJ, Puyalto M, Kim WK, Applegate TJ. Sodium butyrate improved performance while modulating the cecal microbiota and regulating the expression of intestinal immune-related genes of broiler chickens. Poult Sci. 2017;96:3981-93. https://doi.org/10.3382/ps/pex218.

68. Meehan CJ, Beiko RG. A Phylogenomic view of ecological specialization in the Lachnospiraceae, a family of digestive tract-associated bacteria. Genome Biol Evol. 2014;6:703-13. https://doi.org/10.1093/gbe/evu050.

69. Reeves AE, Koenigsknecht MJ, Bergin IL, Young VB. Suppression of Clostridium difficile in the gastrointestinal tracts of germfree mice inoculated with a murine isolate from the family Lachnospiraceae. Infect Immun. 2012; 80:3786-94. https://doi.org/10.1128/IAl.00647-12.

70. Torok VA, Allison GE, Percy NJ, Ophel-keller K, Hughes RJ. Influence of antimicrobial feed additives on broiler commensal posthatch gut microbiota development and performance. Appl Environ Microbiol. 2011;77: 3380-90. https://doi.org/10.1128/AEM.02300-10.

71. Diao H, Zheng P, Yu B, He J, Mao X, Yu J, et al. Effects of benzoic acid and thymol on growth performance and gut characteristics of weaned piglets. Asian Australas J Anim Sci. 2015;28:827-39.

72. Nava GM, Attene-ramos MS, Gaskins HR, Richards JD. Molecular analysis of microbial community structure in the chicken ileum following organic acid supplementation. Vet Microbiol. 2009;137:345-53. https:/doi.org/10.1016/j.vetmic.2009.01.037.

73. Tsai $Y$, Cheng $P$, Pan T. The immunomodulatory effects of lactic acid bacteria for improving immune functions and benefits. Appl Microbiol Biotechnol. 2012;96:853-62. https://doi.org/10.1007/s00253-012-4407-3.

74. Hui ST, Parks BW, Org E, Norheim F, Che N, Pan C, et al. The genetic architecture of NAFLD among inbred strains of mice. eLife. 2015;4:1-28. https://doi.org/10.7554/eLife.05607.

75. He B, Hoang TK, Tian X, Taylor CM, Blanchard E, Luo M, et al. Lactobacillus reuteri reduces the severity of experimental autoimmune encephalomyelitis in mice by modulating gut microbiota. Front Immunol. 2019;10:385-97. https://doi.org/10.3389/fimmu.2019.00385.

76. Timbermont L, Lanckriet A, Dewulf J, Nollet N, Schwarzer K, Haesebrouck F, et al. Control of Clostridium perfringens-induced necrotic enteritis in broilers by target-released butyric acid, fatty acids and essential oils. Pediatr Res. 2010;39:117-21. https://doi.org/10.1080/03079451003610586. 